\title{
5.6. Symbolik
}

\subsubsection{Apfel}

Der Apfel ist in Schlagschatten ein häufig auftretendes Symbol. Wie viele Symbole ist auch dieses ambivalent und verkündet nicht nur Leben, sondern auch Tod, ist Symbol der Sünde, aber auch das der Erlösung von der Sünde und des ewigen Lebens. ${ }^{298}$ Das Symbol manifestiert sich in den unterschiedlichsten Schattierungen und unterschiedlichsten Farben wie z. B. rot, golden oder grün.

In einer Szene, in der Richard kurz nach seiner Verwundung beim Juliputsch das Bewusstsein verliert, sieht er eine Magd seiner Kinderjahre ihm einen Apfel hinhalten: „dieser Apfel [...] schien aus Gold, drehte sich in der Hand der Magd, drehte sich von selbst, glühendes Gold, immer größer, immer größer, die goldglühende Sonne..." (Schl., S. 124) Der Apfel und die Erinnerung an die Kindheit sollen in Richard den Lebenswillen erwecken. Ähnlich verhält es sich in einer Szene im Spital, von der Richard nicht weiß, ob er sie geträumt oder im Fieber phantasiert hat. Während er im Koma liegt, und es ihm scheint, dass er einen Baum pflanzt, der auch als Lebenssymbol gedeutet werden könnte, erscheint Leni vor ihm. Er möchte nicht sterben und ruft die junge Frau beim Namen. Ein auf der Bettdecke liegender großer roter Apfel soll ihren Besuch im Spital bezeugen.

Bei der Verleihung der Tapferkeitsmedaille, an der Fürst Starhemberg selber teilnimmt, sieht Richard das Gesicht der alten Magd oder das Gesicht Lenis, die ihn - einer Fürstin ähnlich - mit einem goldenen Apfel auszeichnet. Ihm ist eine solche Auszeichnung mehr wert als die, die er gerade bekommen hat. Als er dann vom tragischen Tod Lenis erfährt, kommen ihm wieder Assoziationen mit dem Apfel in den Sinn:

Wo war der rote Apfel, der goldene Apfel? dachte er. Die Kerne verfaulen. Oder werden sie zu neuen Trieben? Wird ein neuer Baum wachsen? Kugelförmig wie der Mond, kugelförmige Kronen im Garten, rotgoldene Früchte. Auch dort, wo die Kerne achtlos fortgeworfen, auf der Flucht erschossen, [Hervorhebung - E.M.F.] soso, auf der Flucht erschossen, auch dort wird ein Neues sprießen. Verloren? Verloren geht nichts. (Schl., S. 285)

${ }^{298}$ Wörterbuch der Symbolik, hrsg. v. Manfred Lurker. Stuttgart 1991 (= Kröners Taschenausgabe, Bd. 464), S. 41. 
Eine solche Überlegung, die sich des Bildes eines von fortgeworfenen Kernen sprießenden neuen Baumes bedient, enthält trotz ihrer tragischen Aussage doch einen Funken vager Hoffnung auf eine bessere Zukunft. In dieser Symbolik tritt die tiefe Verbundenheit des Autors mit der Natur hervor.

Es gibt noch andere Bedeutungen des Apfel-Symbols, es bezieht sich auf das verbotene Verhältnis Richards mit seiner Schwägerin: „Elisabeth hatte große reife Äpfel“" (Schl., S. 124). Er kann ihrer Versuchung nicht widerstehen, sie ist für ihn die Versinnbildlichung des Bösen, sie reicht ihm, wie Eva dem Adam im Paradies, einen Apfel vom verbotenen Baum. Deshalb nimmt er seine Verwundung als eine verdiente Strafe hin.

\subsubsection{Braun}

Diese Farbe ist in Schlagschatten eine eindeutig faschistisch-nationalsozialistische Symbolfarbe. Die NS-Ideologie fand auch in Farbund Bildsymbolen ihren Niederschlag. Eines ihrer Elemente war die braune Farbe, die seit 1925 die bevorzugte Farbe der Nationalsozialisten war. Das derbe, erdverbundene Braun war die Uniformfarbe der SA, der politischen Leiter und der Hitler-Jugend, außerdem wurde Hitlers Parteizentrale in München als das „Braune Haus“ bezeichnet. $^{299}$

Braun tritt vor allem im Kapitel Hans zutage, denn dieser Protagonist kommt am häufigsten mit den Nationalsozialisten in Berührung. Bei seinem Fluchtversuch aus der Tschechoslowakei sieht Hans Brünner die braune Flut der Thaya: „Das dünne Gerinnsel zog eine kleine, helle Strömung, einen grünen Faden in das breiige Braun." (Schl., S. 221) Vom Gefängnisfenster kann er ein Feld und eine „Schar Tauben auf dem frisch geeggten Braun" sehen (Schl., S. 237). Er beobachtet auch den Himmel und die sich in ihm widerspiegelnden Gefängnismauern, die im Kontrast zum blauen Himmel graubraun sind. Auf der Flucht aus dem Zug, bei der ihm Nazis helfen, nimmt er hellgrüne Sträucher mitten im struppigen braunen Eichenbuschwerk wahr. (Schl., S. 252) Bei seinem Treffen mit einem Nationalsozialisten, der ihm gefälschte Papiere gibt, sieht er eine das braune Laub des Vorjahres wegkratzende und darunter nach Futter pickende Amsel. (Schl., S. 259)

${ }^{299}$ Ebd., S. 195. 
Diese in der Natur verwurzelte Symbolik könnte einerseits die Gefahr des kommenden Nationalsozialismus bedeuten, aber andererseits gleichzeitig die Möglichkeit, dieser Gefahr noch vorbeugen zu können. Das ist an der zu neuem Leben erwachenden Natur sichtbar.

\subsubsection{Vögel}

In beiden Romanen, besonders aber in Schlagschatten, erscheinen zahlreiche Vögel, deren Präsenz eine symbolische Bedeutung beigemessen werden kann. Es sind verschiedenartige Vögel wie Waldkauz, Krähe oder Adler, der als Symbol des imperialen Herrschaftsanspruches $^{300}$ seine Schwingen über dem Hakenkreuz spannt und über dem Tor eines öffentlichen Gebäudes prangt (TV, S. 32). Die größte Rolle spielen jedoch Bussard und Lerche, die entweder Unheil und Tod ankündigen, oder als Symbol der Freiheit und Lebenslust auftreten.

\section{Bussard}

Als Richard den kleinen Helmut rettet, hört er unter den Stimmen der aufgeregten Frauen den Ruf eines Bussards: „Klagend, zierlich klang der Ruf des großen Vogels, fast zu zierlich für seine Größe, fast zu klagend für seinen stolzen Flug." (Schl., S. 13) Nur er allein kann das hören, es scheint ihm kein gutes Zeichen zu sein.

Während des Treffens mit Franz Prannowitz, der ihm den Tod seiner Schwester mitteilt, sieht Richard wieder einen Bussard. Bevor er die Todesnachricht hört, sieht er den Vogel seine Kreise ziehen. Nur ab und zu dringt zu seinen Ohren ein abgerissener Schrei. Nachdem er die Nachricht erhalten hatte, hört er den „Bussard schreien, lang und klagend, wieder und wieder" (Schl., S. 283). Als ihn Franz $\mathrm{zu}$ beruhigen versucht, verschwindet der Bussard. Richard überlegt, ob er zugestoßen hat. Die Jagd eines Raubvogels auf seine Opfer kommt der Ermordung einer schuldlosen Frau durch die Exekutive gleich.

Der Flug eines Raubvogels ist an einer anderen Stelle ein Zeichen eines sich erst ankündigenden Unheils. Als Hans mit dem tschechischen Mädchen Anna einen Spaziergang macht, sieht nur sie einen Raubvogel und weiß, dass er sich bald auf sein Opfer stürzen wird.

${ }^{300}$ Ebd., S. 6. 
(Schl., S. 188) Während Anna die Aufmerksamkeit Hansens ablenkt, sind ihr Vater und der Nazi Karel mit dem Schmuggel von Waffen und anderen Waren beschäftigt. Der klagende Schrei des Raubvogels könnte aber auch das Ungluick vorausdeuten, zu dem es kommt, als Karel versucht Anna zu vergewaltigen, was für ihn einen tödlichen Ausgang hat, da er vom herankommenden Hans nach einem kurzen Kampf erschossen wird.

\section{Lerchen}

Als Hans nach seiner Flucht wieder frei ist, hört er Lerchen in der Luft trillern. Der Nazi hört sie jedoch nicht. Als er ihm gefälschte Dokumente und eine Pistole gibt, kommt Hans auf die Idee, ihn zu erschießen. Plötzlich verstummen die Vögel. Als er zu dem Schluss kommt, dass er seinen Feind ohne von ihm angegriffen zu werden, nicht ermorden kann, hört er wieder die Lerchen singen. (Schl., S. 257-259) Der Lerchengesang, der Duft und das Licht tragen dazu bei, dass er die Vergangenheit vergessen und nach Wien zu seiner Frau und seinen Genossen zurückkommen möchte. In seiner Wiener Wohnung fühlt er sich beengt, dort gibt es keinen Vogelgesang. Nachdem er seiner Frau wieder nähergekommen war, fühlt er sich, als ob er die Lerchen im blauen Himmel über dem Hohlweg singen hören würde. (Schl., S. 263)

Es ist kennzeichnend, dass eigentlich nur einige ausgewählte Menschen wie der Förster Richard Wohlleben oder die junge Bauerntochter Anna die Geräusche der Natur wahrnehmen, auch wenn es laute sind, wie der Ruf eines Raubvogels. Es ist die tiefe Naturverbundenheit und besondere Empfindsamkeit, die sie dafür prädestiniert.

In Totale Verdunkelung erfährt dieses Symbol eine Bedeutungsverschiebung. Die Lerchen dienen dazu, den Kontrast zwischen dem Gespräch von Franz Prannowitz mit einer der Mitarbeiterinnen in Richard Wohllebens Büro und einer Szene in Franzens Erinnerung hervorzuheben. Es handelt sich um die Szene, in der er seine russische Geliebte nach einigen Monaten, als er mit seiner Truppe wieder in jenes Gebiet kommt, als verkohlte Leiche wiederfindet. "Er buickte sich, scharrte mit dem Stock weiter und hatte nach wenigen Minuten die größten Teile eines verkohlten Gerippes freigelegt, auf dessen Brust ein winziger Kinderschädel lag [...] Als er das Gerippe aufheben wollte, zerfiel es zu einem wirren Haufen. In der Mitte lag der 
Kopf." (TV, S. 66) Als er bei ihrem Grab steht, hört er über ihm das Trällern einer Lerche und empfindet es als Verhöhnung (TV, S. 67), denn der fröhliche Gesang dieser Vögel scheint ihm hier völlig fehl am Platz zu sein. Bei der Gegenüberstellung dieser Szene mit der empörten Äußerung der Frau in Wohllebens Büro, dass es barbarisch sei, dass Prannowitz in Italien gebratene Lerchen gegessen hat, kommt erst das ganze tragische Ausmaß dieser Szene zum Ausdruck. ${ }^{301}$

\subsubsection{Bilder als Symbole}

Das Bild, das Richard von der alten jüdischen Malerin bekommt, weil sie sich bei ihm auf diese Weise für seine Hilfe bedanken will, scheint ihn am Anfang nicht anzusprechen. „Die großen Augen, fragend auf ihn gerichtet! Gute Bilder? Er verstand nichts davon. Er sah nur die Augen, alles andere setzte sich undeutlich von dem dunklen Hintergrund ab. Manches Mal waren da noch - beschwörend oder betend? erhobene Hände." (TV, S. 174) Als er ein ähnliches Bild im Hause seines Vorgesetzten findet, ist er sicher, dass es eine Arbeit von derselben Hand ist. Erst Frau Perkal formuliert seine Gefuihle, die er dem Bild gegenüber hegt, indem sie sagt, dass sie sich bei dessen Anblick immer verfolgt fühlt oder so, als ob sie auf der Anklagebank säße. „Aber das war es. Das stimmte, diese Bilder klagten an." (TV, S. 179) Im Kontext seines früheren Gesprächs mit der jüdischen Künstlerin fühlt sich Richard an dem Schicksal der Menschen, die auf ihren Bildern dargestellt wurden, schuldig.

\subsubsection{Romantitel}

Die Titel der Romane selber können als Symbole interpretiert werden. Sie weisen, ähnlich wie die Farben, auf die Nähe des Romanciers zur Malerei hin. Ein ,Schlagschatten' bezeichnet in der Malerei oder Fotographie einen scharf umrissenen Schatten, den eine Person oder ein Gegenstand auf einem Bild wirft. ,Totale Verdunkelung' bezieht

${ }^{301}$ In beiden Romanen werden viele Szenen auf ähnliche Weise verbunden, das heißt mittels Bindegliedern, wie sie in dem zitierten Beispiel die Lerchen darstellen. Diese Bindeglieder verbinden viele Erzählstränge, auch die zeitlich sehr entfernten, miteinander. 
sich auf den Militärjargon und bedeutet eine Vorrichtung zum Verdunkeln von Fenstern als Maßnahme des Luftschutzes. ${ }^{302}$

Vereinfachend formuliert könnte die Gradation der Titel Schlagschatten und Totale Verdunkelung das Ausmaß der dem österreichischen Staat seitens des Nationalsozialismus drohenden Gefahr oder das Anwachsen faschistischer Tendenzen in der Bevölkerung bedeuten. Die Handlung des ersten Romans spielt in der Zeit, in der es zumindest theoretisch noch möglich gewesen wäre, diese Gefahr abzuwenden, während im zweiten Roman das NS-Regime zwar seine Blütezeit hinter sich hat, aber immer noch existiert. Die Zeit des Nationalsozialismus wurde oft als dunkler Abschnitt der österreichischen Geschichte, als die „NS-Nacht ${ }^{\star 303}$ bezeichnet. Deshalb ist der Ausdruck „Totale Verdunkelung“ äußerst adäquat. Aus der Nachkriegsperspektive heraus könnte er auch als Wunschdenken vieler Menschen gedeutet werden, dieses Kapitel der österreichischen Geschichte nicht zu behandeln, damit es weiter im Dunkeln bleibt. „Totale Verdunkelung" wird auch als die Haltung der Bevölkerung im Krieg, als eine „Überlebensstrategie, ein Mittel zum Durchhalten, zum Haushalten mit Vorräten und zur Tarnung vor dem Angreifer ${ }^{6304}$ gedeutet.

\subsubsection{Romanschlüsse}

Schlagschatten hat einen offenen, symbolischen Schluss. Als Richard von Franz Prannowitz über den Tod Lenis und ihres Mannes erfährt, ist er tief ergriffen. Er denkt über den Sinn des Kampfes im Februar nach und kommt zum Schluss, dass alle damals verloren haben. „Verloren? Gewonnen? Wer hatte verloren? Wer hatte gewonnen? Leni. Leni. Haben wir nicht alle verloren?" (Schl., S. 286) Auf dem Weg nach Hause hört er einen Wanderer ein Lied singen, das mit den Worten „Hoch auf dem gelben Wagen...“ beginnt. Die letzen Worte des Romans entstammen dem Lied, dessen Worte lauten: , [...] aber der Wagen, der rollt!" (Schl., S. 287) Alois Vogel teilte mir mit, dass dieses Lied oft von jugendbewegten Vereinen nach dem Ersten

${ }^{302}$ DUDEN Deutsches Universalwörterbuch, hrsg. v. Günther Drosdowski. Mannheim, Leipzig, Wien, Zürich: Dudenverlag 1989 (2. Aufl.), S. 1324 und 1638.

${ }^{303}$ Vgl. z.B. Weissensteiner, Friedrich: Der ungeliebte Staat. Österreich zwischen 1918 und 1938. Wien: ÖBV 1990, S. 158.

${ }^{304}$ Dst., AV-Mappe, Wiener Zeitung v. 20.2 2. 1981. 
Weltkrieg gesungen und von den Nationalsozialisten unter anderem wegen der Symbolik eines in die neue Zeit rollenden Wagens übernommen wurde. Dieses Lied sei, nach seinen Worten, ein „typisches Beispiel eines Liedes, das ursprünglich nichts mit der Hitlerpartei zu tun hatte und allmählich von den Trägern dieser Partei sehr gepflegt, gänzlich als Lied ihrer ,Bewegung' ausgegeben wurde. ${ }^{\text {"305 }}$ Dadurch wird deutlich, dass die Zeit der nationalsozialistischen Herrschaft in Österreich unmittelbar bevorsteht.

Der Schluss von Totale Verdunkelung ist ebenfalls symbolhaft. Ehemalige Gegner vom Februar 1934 - Franz Prannowitz und Richard Wohlleben - treffen einander in der Feuerwehrzentrale Am Hof. Sie geben ihre Schuld zu, die das Funktionieren des NS-Systems ermöglicht hat, und fahren gemeinsam zum Einsatz in Richtung Ballhausplatz. Sie möchten die Vergangenheit vergessen: „Ich meine, daß niemand von uns mehr eine solche Uniform anziehen, keiner jemals mehr einen Schießprügel angreifen muß." (TV, S. 196), sagt Wohlleben.

Alois Vogel meint, dass er seine Romane nie in der Absicht der kritischen Versöhnung geschrieben habe, wie ihm das Ernst Glaser ${ }^{306}$ attestieren will, wenn überhaupt, dann neige er zu der Annahme, dass der zweite Roman in diese Richtung tendiere. ${ }^{307}$

\subsection{Reflexion, Psychologie und das Existenzielle}

Alois Vogels Technik der assoziativen Retrospektive kann „als Wieterentwicklung der von Schnitzler in die deutsche Erzählung eingeführten Technik des Stream of consciousness in Kombination mit der von Musil erzielten Aufhebung des zeitlichen Nacheinanders und dem von Hofmannsthal, Musil und Kafka erfahrenen Verlust des ,Ich ' mit der von Bernhard als Konsequenz dazu entwickelten, nahezu permanent relativierten Erzählperspektive betrachtet werden. So gesehen darf diese von Vogel hier entwickelte Erzähltechnik wohl als eine Pionierleistung auf dem Gebiet der erzählenden Prosa betrachtet werden, ${ }^{\text {"308 }}$ fasst August Obermayer Alois Vogels Romantechnik zusammen.

\footnotetext{
${ }^{305}$ Antworten Alois Vogels auf die Fragen der Verfasserin v. 25. 7. 2001.

${ }^{306}$ Glaser: Der Februar 1934 in der Dichtung, S. 257.

${ }^{307}$ Antworten Alois Vogels auf die Fragen der Verfasserin v. 15. 3. 2000.

${ }^{308}$ Obermayer, August: Nachwort zum 4. Band der 5-bändigen Werkausgabe Alois Vogels. Schlagschatten und Totale Verdunkelung. Zwei Romane,
} 
Es scheint, dass es kaum möglich gewesen wäre, den modernen Krieg in seinem Umfang mit der Komplexität der menschlichen Haltungen und Weltanschauungen, als Prozess, der blitzartige Änderungen erfährt und sich aus fast nicht mehr nachvollziehbaren aufeinander folgenden Ereignissen - besonders zum Ende des Zweiten Krieges - zusammensetzt, in Form eines traditionellen Kriegsromans darzustellen - vorausgesetzt, dass man unter diesem Begriff einen Roman versteht, der den Krieg als einen unmittelbaren Vorgang schildert, wobei das Soldatenschicksal unmittelbar von dem sich in der dargestellten Romanwelt abspielenden Krieg abhängt.

Diese Tatsache trägt dem bereits von Hermann Broch erklärten Zerfall der Werte Rechnung, der sich auch in der Gestaltung seines Romans Die Schlafwandler widerspiegelt. Im Angesicht des Zerfalls der Werte hat der Romancier die Aufgabe, für diese Welt und zerfallende Wirklichkeit adäquate Darstellungsmittel zu finden. ${ }^{309} \mathrm{Bei}$ Alois Vogel kommt das durch Betonung bestimmter Aspekte und Weglassen anderer Faktoren zum Vorschein. Stefan Kaszyński, der sich in dem zitierten Artikel mit dem österreichischen Kriegsroman nach 1945 beschäftigt und Alois Vogel mit Totale Verdunkelung als einen der drei Autoren erwähnt, die für diese Kategorie charakteristisch sind, sieht dieses Phänomen folgendermaßen:

Im Mittelpunkt der österreichischen Kriegsromane stehen Randerscheinungen des Zweiten Weltkrieges, das Existenzielle wird mehr als das Ideologisch-Politische in den Vordergrund gerückt, die Reflexion wird zugunsten der Handlung ausgebaut, die Psychologie überwältigt die Technologie. ${ }^{310}$

Davon zeugen die Wahl der Protagonisten, die einfache Menschen sind und deren Schicksale zumindest indirekt vom Krieg beeinflusst werden, die Wahl der Handlungszeit, die in beiden Romanen lediglich einige Monate, beziehungsweise einige Wochen umfasst, die ausgewählte Erzähltechnik, die sich mehr auf die inneren Erlebnisse der Helden als auf die äußeren Geschehnisse konzentriert und die Spra-

hrsg. v. August Obermayer und Wendelin Schmidt-Dengler. Wien, München: Deuticke 1999, S. 479-487. Zitat S. 487.

${ }^{309}$ Schmidt-Dengler, Wendelin: Roman und Romantheorie im zwanzigsten Jahrhundert. Skriptum zur Vorlesung. Wintersemester 1997/ 1998. Wien: Basisgruppe Germanistik o. J., S. 75.

${ }^{310}$ Kaszyński: Der österreichische Kriegsroman nach 1945, S. 1097. 
che, die die unterschiedlichen Charaktere der Romangestalten wiedergibt.

Man könnte Vermutungen anstellen, warum Alois Vogel sich einer solchen Technik bediente. Diese Form entspringt einerseits der Tatsache, dass der zeitliche Abstand zwischen den im ersten Roman beschriebenen Ereignissen und der Abfassungszeit des Romans über dreißig Jahre beträgt. Diese zeitliche Distanz kann die Darstellungsweise entscheidend beeinflusst haben. Ereignisse, die festgehalten werden, direkt nachdem sie sich abgespielt haben, werden in der Regel anders verarbeitet als solche, die erst einige Jahrzehnte nachdem sie stattgefunden haben, beschrieben werden. Derselben Periode widmete beispielsweise Jura Soyfer sein Romanfragment So starb die Partei, ${ }^{311}$ das er direkt nach den Ereignissen niederschrieb. Er war der einzige österreichische Autor, der schon in den dreißiger Jahren eine umfassende Darstellung des Februar 1934 und seiner Vorgeschichte versuchte. $^{312}$ Bei ihm wird die Chronologie beibehalten. Im Falle Vogels kann diese zeitliche Entfernung dazu beigetragen haben, dass das Aufeinanderfolgen der Geschehnisse weniger zählt als das Assoziative, das durch Rückblenden und Zeitsprünge sichtbar wird. Andererseits ist es auch die dezidierte Absicht des Autors, den Inhalten seiner Romane eben diese Form zu verleihen. Er hält sich nicht allzu genau an die Chronologie, die im Roman dargestellte Zeit wird oft durch Erinnerungen oder Assoziationen durchbrochen. Es war nicht seine Absicht eine Biographie zu schreiben, die eine bestimmte Form aufzwingt und in der Chronologie eine entscheidende Rolle spielt.

\subsection{Sprache}

Die Palette der Stile und Sprachebenen, der sich Alois Vogel in seinen Romanen bedient, reicht von der poetischen Sprache der Na-

${ }^{311}$ Soyfer, Jura: So starb die Partei. In: Jura Soyfer. Das Gesamtwerk. Prosa, hrsg. v. Horst Jarka. Wien, München, Zürich: Europaverlag 1984, S. 94222 .

${ }^{312}$ Horst, Jarka: Einleitung. In: Jura Soyfer. Das Gesamtwerk. Prosa. Wien, München, Zürich: Europaverlag 1984, S. 7-16, hier S. 14. Es wird von Jarka betont, dass sich in jener Zeit außer Jura Soyfer nur deutsche Autoren wie Anna Seghers und Friedrich Wolf mit diesem Thema befasst haben. 
turbeschreibungen bis zum Soldatenjargon, in dem die Taten der deutschen Soldaten in Serbien beschrieben werden.

Im Gegensatz zum Roman Mars im Widder Alexander LernetHolenias, der einer anderen, früheren Schriftstellergeneration angehörte - scheut Vogel nicht vor Begriffen wie Nationalsozialismus, Gestapo, SS oder Konzentrationslager, die nunmal zum letzten Weltkrieg dazugehören, zurück. Die Sprache Lernet-Holenias war dagegen völlig frei von derartigen Termini. Stefan Kaszyński nennt seinen Roman überspitzt eine „,Kriegsdarstellung für die ,Dame”“" und stellt fest, dass Holenia an der Darstellung der Gründe und politischideologischer Zusammenhänge nicht interessiert sei. ${ }^{313}$ Dies kann man uber Alois Vogels Romane auf keinen Fall sagen. Im Gegenteil, einer der Gründe für seine literarische Tätigkeit ist die Tatsache, dass er mit seinem Schaffen Zeugnis ablegen will. Seine Haltung ist nicht von der Annahme geprägt, dass man nach dem Krieg nur dort wieterzumachen brauche, wo man durch den Anschluss 1938 unterbrochen wurde, sondern setzt eine zwar schmerzhafte, aber notwendige intensive Auseinandersetzung mit der damals jüngsten Vergangenheit voraus. Seine Romane bezeugen, dass das Bewusstsein der Teilnahme der Österreicher am Verbrechen gegen die Menschheit während des Zweiten Weltkrieges ständig präsent ist.

In beiden Romanen gibt es auch außer der typischen Nomenklatur des Dritten Reichs viele Dialektworte und -ausdrücke. Im vierten Band der Werkausgabe wurde eine Liste mit Erklärungen angefertigt, die unter anderem solche Redewendungen erläutert. Dort kann man erfahren, dass „Greißler“314 für einen kleinen Lebensmittelhändler, „Gstätten“ für eine Müllhalde oder ein verwahrlostes Stück Land, "Schippel“ für eine Menge, „trogat" für trächtig, schwanger oder „Krampen“ für eine Spitzhacke steht, um nur einige Beispiele zu nennen. In beiden Romanen treten viele Bezeichnungen auf, die die damalige Situation näher zu beschreiben ermöglichen und für den heutigen Leser nicht immer ganz verständlich sind. So zum Beispiel der „Biertippler", der in Schlagschatten nicht einen ,gewohnheitsmäßigen Biertrinker' bezeichnet, wie es das DUDEN Wörterbuch ${ }^{315}$ angibt, sondern einen Vagabunden, der die Bierreste aus den abservierten

${ }^{313}$ Kaszyński: Der österreichische Kriegsroman nach 1945, S. 1098.

${ }^{314}$ s. Anmerkungen zu Schlagschatten und Totale Verdunkelung. In: Schlagschatten und Totale Verdunkelung. 4. Band der 5-bändigen Werkausgabe Alois Vogels, S. 489-493.

${ }^{315}$ DUDEN, S. 258. 
Gläsern trinkt. Wenn Bezeichnungen wie „Zigarettenstummelsammler" oder "Hausierer" dem Leser noch ein Begriff sein mögen, so ist er sicherlich weniger vertraut mit Ausdrücken wie „Bettgeher", der ebenso viel wie ,Schlafgänger' bedeutet, das heißt eine Person, die sich kein eigenes Zimmer leisten kann, sondern nur stundenweise eine Schlafstelle mietet, die während der Nacht von den Vermietern benützt wird, oder „Mistkübelstierer“, der einen verarmten Menschen bezeichnet, der Mülleimer nach Brauchbarem durchsucht. Diesem Vokabular kann man eine wichtige Bedeutung zuschreiben, diese Wörter fungieren als Geschichtssignale unterschiedlicher Art im Sinne Hugo Austs.

\subsection{Die Stimmigkeit mit historischen Fakten}

In einem früheren Kapitel wurden positive Kritiken zitiert, die besagen, dass die Romane Alois Vogels authentisch wirken, dass die Atmosphäre jener Zeit treffend dargestellt wird. Was macht diese Authentizität aus? Wie erzeugt der Romancier diese Stimmigkeit der Umstände?

Sicherlich liegt das unter anderem an der exakten Schilderung dieser Atmosphäre, die sich vor allem aus der Darstellung des Alltags der Durchschnittsbürger, aus soziokulturellem, wirtschaftlichem und politischem Hintergrund zusammensetzt. Alois Vogel bestätigt, dass er während der Arbeit an Schlagschatten sehr viele Zeitungen verschiedener Richtungen gelesen hat, um sich einen entsprechenden Hintergrund zu erarbeiten. ${ }^{316}$ "Für beide Romane bedurfte ich vieler zeitgeschichtlicher Unterlagen, die ich in der Bibliothek der Stadt Wien im Rathaus fand. Auch befragte ich viele ältere Menschen [...], Menschen aus verschiedenen sozialen Schichten, die unterdessen verstorben sind, um gewisse Situationen. ${ }^{\text {“317 }}$

Die meisten dieser Umstände werden ziemlich genau und wirklichkeitstreu geschildert, nur wenige weichen von den Fakten ab. Es kann die These gewagt werden, dass insbesondere Schilderungen, die das alltägliche Leben, sowie den kulturellen, sozialen und wirtschaftlichen Hintergrund betreffen, in der Regel der Wirklichkeit entsprechen. Eventuelle Unstimmigkeiten treten an den Stellen auf, die sich

\footnotetext{
${ }^{316}$ Brief Alois Vogels v. 3.7.2000.

${ }^{317}$ Brief Alois Vogels v. 4. 8. 2001.
} 
auf historische Begebenheiten beziehungsweise Gestalten beziehen. Wie bereits festgestellt wurde, kommen historische Gestalten in diesen Romanen äußerst selten vor, historische Begebenheiten stehen auch nicht im Zentrum des Interesses. Deshalb ist die Zahl der festzustellenden Unstimmigkeiten gering. Eine Schreibweise, die sich auf fiktive Figuren, von denen die Handlung getragen wird, konzentriert, verringert die Gefahren, die bei der Darstellung geschichtlicher Persönlichkeiten entstehen und notgedrungen mit Verfälschungen verbunden sind.

\subsubsection{Der kulturelle Aspekt}

Film, Theater und Literatur

Film, Theater und Literatur wurden in der Ära des Nationalsozialismus mit propagandistischen Inhalten durchsetzt. Dieser Zustand findet in Totale Verdunkelung seinen Niederschlag. Anhand eines jungen Mädchens namens Poldi Mihatsch, das im Jahr 1944 zweiundzwanzig Jahre alt ist, wird skizzenhaft die Bedeutung des Films geschildert, der in der Nazipropaganda eine große Rolle spielte. So ist beispielsweise von den Wochenschauen die Rede, die oft "tote Soldaten [zeigten], doch meist waren es die der Feinde. Sicher, manchmal auch Deutsche, doch die Leinwand war kühl und distanziert" (TV, S. 120). Die Wochenschauen, die seit Oktober 1938 von den Kinobesitzern verbindlich vorgeführt werden mussten, hatten während des Krieges einen eigenen Stil entwickelt, der darauf beruhte, dass „realistische" Bilder mit entsprechenden Kommentaren und heroischer Musik unterlegt wurden. Dabei achtete das Propagandaministerium sehr darauf, dass wesentliche Aspekte der Kriegsrealität, vor allem eigene Verluste und feindlicher Widerstand, ausgespart blieben. ${ }^{318}$ Das entspricht völlig dem von Vogel gezeichneten Bild, das er dem Leser mit den Augen eines jungen, unerfahrenen und daher für solche Inhalte sehr aufnahmefähigen Mädchens vorführt. Dasselbe Mädchen bewundert den Film von Leni Riefenstahl Das blaue Licht, dessen Handlung sich in der "herrlichen Bergwelt" (TV,

${ }^{318}$ Longerich, Peter: Nationalsozialistische Propaganda. In: Deutschland 1933-1945. Neue Studien zur nationalsozialistischen Herrschaft, hrsg. v. Karl Dietrich Bracher, Manfred Funke, Hans-Adolf Jacobsen. Bonn: Bundeszentrale für politische Bildung 1993, Bd. 314, S. 291-314, hier S. $306 f$. 
S. 119) der Heimat abspielt. Der Film selber war kein Propagandafilm im engeren Sinne, wie andere Filme dieser Regisseurin, zum Beispiel Sieg des Glaubens oder Triumph des Willens, ${ }^{319}$ die den Parteitag der NSDAP dokumentiert haben. Er konnte aber als Verherrlichung der Heimat viel diskreter zu Propagandazwecken verwendet werden als typische Propagandafilme. Das Mädchen schwärmt auch von den jungen, immer bekannter werdenden Schauspielern Fred Liewehr und Ewald Balser $^{320}$ (TV, S. 121).

Leichtgläubigkeit und politische Naivität Poldis machen sie zum beliebten Ziel der Propaganda. An ihrem Beispiel wird aufgezeigt, auf welche Art und Weise die Jugend in der Zeit des Nationalsozialismus indoktriniert wurde. Poldis politische „Aufklärung“ kristallisiert sich unter anderem unter dem Einfluss eines Films, in dem die Darstellerin „wegen eines bösen Juden ins Wasser gehen musste.“ Der Leser erfährt, dass der Film sie tief berührt hat, ihr - wie es heißt - „einen heißen Tränenstrom [entlockte]" (TV, S. 120). Der Film allein hätte bei ihr keinen so starken Eindruck hinterlassen. Sie bringt ihn aber in Zusammenhang mit der Absetzung eines Theaterstuicks Lessings auf Grund der Ringparabel ${ }^{321}$ und mit dem Verschwinden der Bücher Heinrich Heines aus den Buchhandlungen, dessen Gedichte sie eigentlich gerne gelesen hatte. Sie protestiert nicht, als ihre Mutter

${ }^{319}$ Ebd., S. 307 u. 312.

${ }^{320}$ Ewald Balser befindet sich auf der Liste der prominenten Schauspieler, die in den deutschen Filmen der NS-Zeit aufgetreten sind mit dem Pauschalhonorar in der Höhe von 35000 RM, s. Drewniak, Bugusław: Der deutsche Film 1938-1945. Ein Gesamtüberblick. Düsseldorf: Droste 1987, S. 162.

${ }^{321}$ Direkt war das im Roman nicht gesagt, aber es ist allgemein bekannt, dass diese Ringparabel dem Stück Gotthold Ephraim Lessings Nathan der Weise entstammt. Es gab einen reichen Mann, in dessen Familie ein Brauch gepflegt wurde, dass der Vater dem Sohn, der dessen am meisten würdig ist, auf dem Sterbebett einen Ring schenkt. Der Beschenkte soll dann Erbe und Haupt der Familie sein. Da der Vater sich nicht entscheiden konnte, welcher der drei Söhne den Ring bekommen sollte, ließ er noch zwei gleiche nachmachen. Letzten Endes hat jeder seiner Söhne einen Ring erhalten. Somit ist die Frage, wer der rechtmäßige Erbe des Vaters sei, unentschieden. Genauso verhält es sich mit den drei Religionen, alle drei hat Nathan für gleichwertig gehalten, was von seiner Toleranz zeugt, was aber von den Nationalsozialisten selbstverständlich nicht geduldet werden konnte. Schauspielführer $A-Z$, hrsg. v. Karl Heinz Berger, Kurt und Gerda Böttcher, Ludwig Hoffmann u.a. Berlin: Henschelverlag Kunst und Gesellschaft 1988, Bd. 2, S. 755f. 
sagt, dass sie Heine nicht lesen solle, weil er Jude war. Dies scheint ihr in Anbetracht des gesehenen Films ein ausreichender Grund zu sein. Bemerkenswert ist auch die Tatsache, inwiefern sich die Propaganda auf ihre Sprache auswirkt, das heißt ihre Sprache passt sich allmählich der Sprache der Propaganda an. Das Schliusselwort „Judenfrage“, das sehr oft in der Zusammensetzung „Endlösung der Judenfrage" vorkommt, benutzt sie auch, aber sicherlich nicht ahnend, was für ein Themenkomplex damit verbunden ist. ${ }^{322}$

Es ist unschwer zu eruieren, um welchen Film es sich im Roman handelt, besonders da die Schauspielerin genannt wird. Es handelt sich hierbei um eine Schwedin, die zuerst im deutschen Film Karriere gemacht hat - Kristina Söderbaum. Das Mädchen mit den veilchenblauen Augen und dem Blondhaar, das als ein Ideal einer ,,nordischen Schönheit" gegolten hat, wurde gern für propagandistische Zwecke eingespannt. Sie wurde ein Stern erster Größe. Ihre Filme spielten mehr als 200 Millionen Mark ein. Sie wurde vom Publikum „Reichswasserleiche" genannt, denn in den Filmen, in denen sie spielte, wurde sie mit einer gewissen Regelmäßigkeit ins Wasser getrieben. ${ }^{323}$ Die Vermutung, dass es sich hier um die repräsentative Spielfilmproduktion des Dritten Reiches, um den antisemitischen Film Jud Sü $\beta$ handelte - hat Alois Vogel bestätigt. Er stellte fest, dass im Hintergrund stehe, dass die junge Rot-Kreuz-Schwester an diesen Film dachte, auch wenn der Titel nicht genannt wird, ${ }^{324}$ ähnlich wie es bei

${ }^{322}$ Es muss hier auf den Mechanismus hingewiesen werden, der in der Zeit des Nationalsozialismus und sicherlich auch in anderen totalitären Regimes funktionierte und darauf beruhte, dass hinter scheinbar harmlosen Begriffen wie z.B. „Arisierungen” oder "Euthanasie" grausame Inhalte wie der Raub des jüdischen Vermögens oder die Ermordung der Alten und Kranken versteckt wurden: Mittels einer solchen bürokratischen und wissenschaftlichen Versachlichung wurde auch der Massenmord an Juden und anderen Nationen in einen „unpersönlichen Berufsvorgang" verwandelt. Vgl. Steinert, Marlis, G.: Deutsche im Krieg: Kollektivmeinungen, Verhaltensmuster und Mentalitäten. In: Deutschland 1933-1945. S. 474-487, hier S. 485.

${ }^{323}$ Drewniak: Der deutsche Film, S. $137 \mathrm{f}$.

${ }^{324}$ Brief Alois Vogels v. 3.7.2000. Kristina Söderbaum spielte auch in einem anderen äußerst erfolgreichen Film, dem zweiten Farbfilm in der Geschichte des deutschen Films, die Hauptrolle. Sein Titel lautete Die goldene Stadt. Söderbaum ertränkt sich aus Verzweiflung im Moor, in dem schon ihre Mutter ertrunken ist. s. Drewniak: Der deutsche Film, S. $669 \mathrm{f}$. Auch dieser Film ist Poldi bekannt, sie denkt an eine Szene aus dem Film, 
dem Stuick Lessings ${ }^{325}$ der Fall war. Dieser im Auftrag des Reichspropagandaministers gedrehte Film fußte nicht - wie man oft fälschlich angenommen hat - auf der Novelle Wilhelm Hauffs (1827) oder auf dem Roman Lion Feuchtwangers (1925), der 1934 verfilmt wurde und wegen seiner projüdischen Tendenz in Deutschland als Provokation betrachtet wurde. Der Regisseur des antijüdischen Films Jud Sïß, Veit Harlan, machte aus dieser Gestalt eine böse, machtbesessene und abscheuliche Figur. Er erpresst und misshandelt eine junge Frau (gespielt von Kristina Söderbaum), die er nicht heiraten durfte, indem er ihren Mann einsperren lässt. Die junge Ehefrau, die ihren Mann retten will und zu ihm kommt, begeht am Ende Selbstmord, indem sie sich im Neckar ertränkt. Als Strafe wurde Süß aufgehängt, alle anderen Juden mussten das Land verlassen. Die Welturaufführung dieses Films fand am 5.9.1940 während der Filmschau in Venedig statt. ${ }^{326}$

\section{Bïldende Künste}

Über die Größe des deutschen „Geistes" und der deutschen Kultur sprechen in Totale Verdunkelung unter anderem Vorgesetzte eines der Haupthelden, Franz Prannowitz, der in einer Druckerei arbeitet. Sie sind beide Funktionäre der NSDAP, die von der Kultur keine Ahnung $\mathrm{zu}$ haben scheinen. Sie sind aber von der Mission der deutschen Nation in ganz Europa überzeugt: „Unter Adolf Hitler werden wir Deutschen dieser großen Bestimmung nachkommen und werden unsere deutsche Kultur und Sitte bis in den entlegensten Winkel der verlottertsten polnischen Nester bringen. [...] Wir werden ganz Europa zivilisieren." (TV, S. 101) Sie bedienen sich lediglich des schemenhaften Wissens über Kultur und Geschichte, der eine weiß

in der eine der männlichen Gestalten der Söderbaum mit der Hand von der Schulter zur Brust hingleitet. Sie erinnert sich an diese Episode in dem Augenblick, wenn Franzens Hand auf ihrem Arm liegt. Das Weitere kommt - zu ihrer Unzufriedenheit - nicht. (TV, S. 122).

${ }^{325} \mathrm{TV}, \mathrm{S} .121$.

${ }^{326}$ Bemerkenswert war auch die Filmbesetzung. Alle jüdischen Rollen außer der Titelrolle, unter anderen die des Rabbiner Loews, seines Sekretärs, eines Großvaters, eines jüdischen Schlächters und sogar einer jüdischen Frau, wurden von einem einzigen Schauspieler (Werner Krauss) gespielt. Vgl.: Drewniak: Der deutsche Film, S. $313 \mathrm{ff}$. 
nicht einmal den richtigen Namen des damals führenden Bildhauers Arno Breker, er meint, er heiße Bäcker.

Dabei sind sie für die Entstehung eines Albums über Kunst und Architektur verantwortlich und lassen die von den Kunstexperten als besonders empfohlenen Bilder herausnehmen, indem sie sie auf folgende Weise kommentieren:

Das soll ein menschlicher Körper sein. Ein steifes Brett, dieser Brustkorb, das ist doch viel zu flach, Mensch, das sind doch keine Proportionen, das sieht jedes Kind. [...] Das ist eine Verzerrung des deutschen Menschenbildes, das ist eine Verunglimpfung der deutschen Wesensart! (TV, S. 102f.)

Demgegenüber sind ihres Erachtens Skulpturen von Breker Ausdruck der Kraft, die im deutschen Volke steckt, sie bezeichnen sie als „herrliche Menschen“ im Gegensatz zu ,,solche[n] häßlichen Wesen, wie sie uns diese sogenannten Künstler in den zwanziger und dreißiger Jahren vorgesetzt haben" (TV, S. 102). Von der expressionistischen Kunst halten sie selbstverständlich nichts.

Die hier angedeutete Einstellung ist typisch für das Denken der Nationalsozialisten über Kunst, die durchaus politisiert und auf keinen Fall autonom war. Über ihre Qualität haben nicht Fachleute oder einfach für das Schöne empfängliche Menschen entschieden, sondern die von der Partei ausgewählten Pseudospezialisten, die sich den Richtlinien der Parteipropaganda für Kulturpolitik meistens blind untergeordnet haben. Es wird die so genannte „Entartung“ der Kunst und Verdammung der modernen Künstler angesprochen, wobei nicht direkt gesagt wird, was außer der körperlichen Kraft diese deutsche Wesensart eigentlich ausmacht. Eben dies erwies sich in Wirklichkeit als ein Kardinalproblem. Das „Artgemäße“, „Deutsche“ der Kunst war jenseits der geographischen Herkunft nicht zu fassen. „Mehr als Richard Wagners, Deutsch sein heißt klar sein' hatte man nicht mehr zu bieten."327 Die Erwähnung Arno Brekers, des nationalsozialistischen Superstars im Bereich der Bildhauerei, ist hier durchaus beabsichtigt. Seine ,muskelbepackten, oberflächengeglätteten, entindividualisierten Männerakte wurden zu Wahrzeichen des NS-Staates schlechthin ${ }^{6328}$ und standen unter anderem im Innenhof der Neuen

${ }^{327}$ Dussel, Konrad: Der NS-Staat und die „deutsche Kunst”. In: Deutschland 1933-1945, S. 256-272. Zitat S. 261.

${ }^{328}$ Ebd., S. 263. Der Autor des Artikels unterstreicht, dass die Skulpturen von Breker sich eigentlich, wenn man sie isoliert vom historischen Kontext be- 
Reichskanzlei, von der der Betriebsleiter in Totale Verdunkelung mit Entzücken spricht.

Eine Gegenüberstellung der deutschen „Wesensart“, die sich unter anderem in den Skulpturen Arno Brekers ausdruicken sollte, mit der anschließenden Beschreibung vom skandalösen Benehmen der deutschen Soldaten während des Krieges in Serbien ist eine hervorragende erzählerische Leistung. Der Erzähler braucht dies nicht zu kommentieren, der aufmerksame Leser wird selbst entsprechende Schlüsse ziehen. Hier ein Bericht von einem gewissen Wolf, der mit Richard Wohllebens Bruder Erich zusammen in Serbien war:

[...]wenn wir voll waren, haben wir dann einen Feuerzauber veranstaltet. Ein Mordsspaß! Die Glühbirnen mit den Pistolen ausgeschossen. Na, die Weiber haben geschrien. Oder beim Austreten! Was soll ich dir sagen, gleich unter den Tisch. Den Hosenlatz auf und hinuntergeplätschert, damit man nur ja keine Runde versäumt, schön warm unter den Tisch, zwischen die Stiefel und dabei gleichzeitig ein Glas Bier oben nach, daß du einen richtigen Druck auf die Blase bekommst, ist sowieso gleich zwischen den Brettern am Boden versickert. $\mathrm{Na} \mathrm{ja}$, die Weiber, die haben nur so getuschelt, wenn da einer von uns den Schwanz herausgezogen hat. [...] wir waren voll wie die Badeschwämme, und der Wohlleben hat einen Knüppel gehabt, [...] der hätte des Teufels Großmutter gevögelt. (TV, S. 104)

Der lebendige, ordinäre Soldatenjargon trägt dazu bei, dass diese Geschichte überzeugend und glaubwürdig wirkt.

\section{Rundfunk}

Unter den Propagandamitteln der NSDAP war der Rundfunk eines der wichtigsten. Er diente der Steuerung der aktuellen Stimmung und Informationslage, wobei die Informationen oft, besonders bei den für die Bevölkerung nicht erfreulichen Meldungen wie zum Beispiel Bombenangriffe in der Schlussphase des Krieges, eine untergeordnete Rolle gespielt haben. Damit sollte die Bevölkerung von den Alltagssorgen abgelenkt werden. Der Rundfunk war ,weniger ein Instrument gezielter politischer Erziehung und Indoktrination, sondern in erster

trachtete, als inhaltsleer und in nichtfaschistische Umgebungen transportierbar erwiesen. 
Linie darauf ausgerichtet, den Durchhaltewillen der Bevölkerung durch eine ablenkende und einlullende Berieselung mit Unterhaltung zu verstärken. “'329

Auf diese Rolle des Radios wird in Totale Verdunkelung im Gespräch zwischen der jungen Rot-Kreuz-Schwester Poldi und dem Angehörigen der Luftwaffe, Franz Prannowitz, hingewiesen. Er erwähnt Wunschkonzerte, die Soldaten regelmäßig im Radio hören und die sie sehr mitzunehmen scheinen: „Aber freilich hören wir Radio, jedes Wunschkonzert. Die Ilse Werner ${ }^{330}$ Pfeift ja jeder schon mit, wenn sie anfängt. Und die Lale Andersen, ha, ha, oder Heimat, deine Sterne!" (TV, S. 15-16)

Die Sprache der Radionachrichten wird ebenfalls exakt wiedergegeben. An einer Stelle am Ende des Romans wird in den Nachrichten über die Frontsituation und die näherrückende russische $\mathrm{Ar}$ mee, der NS-Bezeichnung entsprechend, der Ausdruck „Niederdonau" beibehalten, der Niederösterreich ersetzt hatte. ${ }^{331}$

Alle oben besprochenen Bereiche, Film, Theater und Literatur sowie bildende Künste und Rundfunk dienten der NS-Propaganda, die Schilderung der zeitgemäßen Umstände ist in der Regel sehr präzise, es werden oft die typischsten Erscheinungen des jeweiligen Bereichs verwendet.

\subsubsection{Der soziologische, wirtschaftliche und politische Hintergrund}

Jugend in der Zeit des Nationalsozialismus, Rolle der Frau im NS-Staat

Dieser Gliederungspunkt soll in zwei Bereiche geteilt werden. Für die Mädchen fungiert die junge Rot-Kreuz-Schwester Poldi wieder als beste Exponentin. Den männlichen Jugendlichen wurde im Roman

\footnotetext{
${ }^{329}$ Longerich: Nationalsozialistische Propaganda, S. 302.

${ }^{330}$ Ilse Werner war eine prominente Filmdarstellerin des Dritten Reiches. Sie war vor allem dafür bekannt, dass sie ihre Lieder gepfiffen hat. Ihre Popularität wurde natürlich auch von finanziellem Erfolg begleitet. Vor Kriegsausbruch betrug ihre Pauschalgage 15.000 RM, während im August $1944 \mathrm{ihr}$ Honorar auf $40.000 \mathrm{RM}$ gestiegen ist, s. Drewniak: Der deutsche Film, S. 153 u. 162.

${ }^{331}$ Hanisch: Der lange Schatten des Staates, S. 363.
} 
weniger Aufmerksamkeit gewidmet, was sich meist in Reflexionen manifestiert. Zum ersten Mal geschieht dies durch Richard Wohlleben, nachdem er auf der Flucht vor der SS einen jungen SS-Mann erschossen hat. Er wird sich bewusst, auf welche Weise man junge Menschen von Kindesbeinen an mit dem NS-Gedankengut getreu dem Sprichwort „Wer die Jugend hat, hat die Zukunft ${ }^{\star 332}$ infiltriert hat.

Was konnte dieser Mensch anderes kennen als die Phrasen, die man ihm beigebracht hatte. Vierzehn Jahre, vielleicht erst dreizehn, war er, als die genagelten Stiefel über die Ringstraße defilierten, die Menschen unter einem Meer von Hakenkreuzen jubelten. Wie konnte er entscheiden? Wie sollte er nicht glauben, was man ihm sagte? War es nicht schön, zu den Starken zu gehören, eine Waffe zu tragen? In der Schule schon war ihm von Siegfried, von Hagen von Tronje, Gunther und den anderen Recken des Nibelungenliedes erzählt worden. Das Leben eines richtigen Mannes ist immer ein Heldenleben, ist immer ein Sich-Messen mit dem Feind und letztlich der Sieg. Sie haben den jungen Menschen Feinde gegeben, genug Feinde. Sie haben sie unbedingten Gehorsam gelehrt. Demut und Dienst am Nächsten waren Tschandalatugenden. Die Ethik der Sklaven. Nietzsche. Er paßt in das Konzept! (TV, S. 184-5)

Danach kommt Richard zu dem Schluss, dass auch er auf ähnliche Weise sozialisiert wurde, dass ihm in der Schule, mit Ausnahme eines einzigen Lehrers, ähnliche Inhalte vermittelt wurden. „Doch in der nächsten Klasse waren es wieder die Ritter in ihren eisernen Rüstungen, die ins Heilige Land zogen, um mit scharfem Schwert für die Wahrheit und das Heil zu kämpfen. Für das Heil, damals und später." (TV, S. 185)

Ein anderer junger Mensch, der mit Herz und Seele der NSIdeologie verfallen ist, ist der Sohn von Leni und Hans Brünner. Sie wurden verfolgt, weil Hans auf Seite der Sozialdemokraten am Bürgerkrieg des Jahres 1934 teilgenommen hatte. Sein Sohn - damals noch ein Kind - macht ungefähr zehn Jahre später eine vormilitärische Ausbildung der Hitler-Jugend und tut Dienst beim Volkssturm. Sein Onkel, Franz Prannowitz, der nach dem Februar in Wöllersdorf interniert wurde, denkt nicht gerne über seinen Neffen nach. Dabei kann er sich noch daran erinnern, dass er gefürchtet hat, dass Helmut

${ }^{332}$ zitiert nach: Klönne, Arno: Jugend im Dritten Reich. In: Deutschland 1933-1945. S. 218-239. Zitat S. 239. 
bei den Wohllebens, die sich seiner angenommen haben, obwohl sein Vater polizeilich gesucht wurde, verdorben würde und am Ende ,gar noch ein Schwarzer würde" (TV, S. 192). Dabei lernt der jetzt Sechzehnjährige „,mit Panzerfäusten umzugehen“ und ,wird vom Sieg dieses Deutschlands noch überzeugt sein, wenn schon die letzte deutsche Stadt besetzt ist" (Ebd.). Helmuts Großmutter rät Franz ab, Helmut von dieser Idee abbringen zu wollen, da sie meint, dass es sowieso keinen Sinn mache.

Poldi vertritt genau dieselbe Einstellung zum Krieg, Hitlerdeutschland und Hitler wie Helmut. Ihre Haltung kommt im Roman am besten und am häufigsten zum Ausdruck. Sie glaubt ihrem Fuihrer vorbehaltlos und bewundert ihn grenzenlos, hält sich blindlings an alle von den Nazis eingeführten Vorschriften und ist bis zum Ende vom Endsieg überzeugt. Bis zum Ende kann sie an Deutschlands Niederlage nicht glauben. „Das ist vollkommen unmöglich. Der Führer hat es doch versprochen. Hier geht es um deutsche Erde! [...] Man hört die furchtbarsten Dinge, Grausamkeiten, Unmenschlichkeiten, Vergewaltigungen. Wo bleibt das reine Bild der deutschen Frau?" (TV, S. 147) Die militärischen Erfolge setzt sie mit der Verbesserung des materiellen Status der Bevölkerung nach dem Krieg gleich. So meint sie beispielsweise: „Wenn wir den Krieg erst gewonnen haben, werden den Opfern ohnehin alle Verluste ersetzt. Sie werden schöner wohnen denn je." (TV, S. 15) Sie macht sich keine Gedanken darüber, dass es außer den Opfern in der deutschen Zivilbevölkerung noch andere Opfer gibt, deren Verluste durch nichts zu ersetzen sind.

Dabei war es ihr überhaupt nicht klar, was das alles zu bedeuten hatte. Sicher, es gab die SS, die Polizei, den SD, es waren Organisationen wie andere auch [...] Da und dort war ihr ein Trüppchen Juden, die von einem SS-Mann geführt wurden, begegnet. Sie hatte sich noch nie etwas dabei gedacht. Es wird schon seinen Grund und seine Richtigkeit damit haben. Unschuldig werden keine verhaftet. Wer sich loyal verhält, wird in Ruhe gelassen. (TV, S. 145)

Poldi ist bereit, auf dem „Altar des Vaterlandes“ Opfer zu bringen. Als Rot-Kreuz-Schwester und BDM-Mädchen macht sie Dienst auf dem Bahnhof. Sie nimmt an den Heimabenden teil, wo sie unter anderem von der Vererbungslehre Mendels im Sinne der NS-Rassenlehre unterrichtet wird. Die NS-Frauenschaft, zu der ihre Mutter gehört, die Nationalsozialistische Volkswohlfahrt, „Werdende und stillende Mütter" sowie „Mutter und Kind" hält sie für Organisationen, die allen dienlich sein können. Sie rät ihrer Freundin, deren 
Mann nach den Nürnberger Rassengesetzen ein Vierteljude ist, bei ihnen Hilfe zu suchen und scheint nicht zu begreifen, warum ihre Freundin sich nicht an diese Organisationen wenden will.

Über ihre unbeugsame Haltung und ihren durch nichts zu erschütternden Glauben an den Führer spottet oft der dem Krieg gegenüber kritisch eingestellte Franz Prannowitz:

[...]Moral! Sitte! Mein Gott, eine Abmachung zwischen den Menschen. [...] Diebstahl ist unmoralisch, doch im Namen der Allgemeinheit oder des Volkes darf gestohlen werden. [...] Man darf sie wohl nicht zu ernst nehmen, die Moral und Sitte, was? $\mathrm{Na}$, und wie wäre es dann mit uns, Schwesterchen, wenn wir heute miteinander im Namen der Volksgemeinschaft schlafen gingen, hm? (TV, S. 33)

Eine andere Repräsentantin der kritiklos an den Nationalismus glaubenden Jugend ist die Rot-Kreuz-Schwester Ilse, die nur einmal erwähnt wird. Ihr zwanzigjähriger Mann wurde - nach Aussage seines Kameraden - von der EAM, ${ }^{333}$ der griechischen Widerstandsbewegung auf brutale Weise ermordet. Ihm wurde ,alles weggeschnitten, [...] alles, was eben so wegsteht bei einem Mann. Bei der Nase und den Ohren haben sie begonnen und beim Unterleib haben sie aufgehört" (TV, S. 39). Angeblich habe er seine Peiniger angefleht, ihn am Leben zu lassen. Die junge Frau des ermordeten Soldaten möchte dem Bericht seines Kameraden keinen Glauben schenken. Sie ist davon überzeugt, dass er mit dem heiligen Wort „Deutschland“ auf den Lippen eines heldenhaften Todes gestorben sei. Die junge Witwe trägt ihre stolze Trauer vor allen ihren Kolleginnen zur Schau: „Blond wie Siegfried. Zwanzig Jahre. Das Schwert in der Hand, in Etzels brennender Burg. Süß ist der Tod fürs Vaterland. Wir werden weitermarschieren, wenn alles in Scherben fällt. Ein Held. Wer von euch, wer noch hat solch einen Helden?" (TV, S. 38) Über ihr Verhalten sagt eine andere Rot-Kreuz-Schwester ironisch, dass es bei ihr nur „Helden oder Volksverräter“ (Ebd.) gebe.

Im Roman wird auch die enorme Rolle der NS-Propaganda in der „Erziehung“ der Jugend im Sinne der „Blut- und Boden - Ideologie“ betont. Insbesondere Feste und verschiedene Feierlichkeiten waren

${ }^{333}$ EAM (Abkürzung für Ethnikon Apeleftherotikon Metopon = Nationale Befreiungsfront). Wichtigste griechische Widerstandsbewegung gegen die italienische und deutsche Besatzung. Zitiert nach: Alois Vogels Werkausgabe, Bd. 4., S. 493. 
damals eine ausgezeichnete Gelegenheit, um sich zu versammeln und seine Angehörigkeit zu den deutschnationalen Vereinen $\mathrm{zu}$ demonstrieren. Richard Wohlleben war im Juni 1938 - also kurz nach dem Anschluss - Zeuge einer solchen Versammlung. Der Anlass dazu war die Sonnwendfeier. ${ }^{334}$ Eine flammende Rede an die zahlreich versammelte Jugend hat damals ein gewisser Dr. Mayerhofer gehalten. Anschließend sprach noch ein Mann in brauner Uniform, der bis zum Anschluss ein Schneidergeselle gewesen war, und daher nicht so uberzeugend sprechen konnte wie der Wissenschaftler, „vom Bollwerk gegen den Osten, von den Taten des Führers und dem Kampf der Partei" (TV, S. 107). Seine Rede beendete er mit erhobener Hand und dem Ausruf: „Ein Volk! Ein Reich! Ein Führer! Sieg Heil! Sieg Heil! Sieg Heil!"“ (Ebd.) Das Publikum, zuerst ein bisschen uiberrascht, schloss sich dem schnell an: „[...] einige fielen schon bei ,Ein Reich!' in den Ausruf ein. Die meisten schlossen sich dann bei ,Sieg heil!' an (Ebd.). Die ganze Veranstaltung war angemeldet und von einem Feuerwehrmann und einem Polizisten betreut.

In Totale Verdunkelung wird die "Dressur der Jugendlichen zur Systemanpassung, zum Verzicht auf politische und gesellschaftliche Willensbildung und Spontaneität, “335 die zur völligen politisch-gesellschaftlichen Entmündigung der Jugend führen sollte, deutlich sichtbar. Erinnern wir uns an die Selbstverständlichkeit und zugleich Beschränktheit, mit der Poldi Mihatsch an das Funktionieren der NSDAP und all ihre Gliederungen denkt oder an die Verzweiflung der Großmutter ihrem Enkel Helmut Brünner gegenüber, der für Deutschland zu sterben bereit ist. Es gibt im Roman keinen einzigen jungen Menschen, der nicht der Hitlerjugend angehört, denn seit Fruihjahr 1940 wurden alle zehnjährigen Jungen und Mädchen verpflichtend zur HJ eingezogen. ${ }^{336}$ Ihre Lebensformen wie Heimabend, Fahrt und Lager werden bei Vogel ebenfalls erwähnt. Die Erfahrung von Brutalität, die zum Bestandteil kindlicher oder jugendlicher „Normalität“" wurde, wird in irgendeiner Form allen jungen Menschen in Totale Verdunkelung zuteil.

${ }^{334}$ Longerich weist daraufhin, dass die Nationalsozialisten einen Zyklus von Feiertagen schufen, der in Konkurrenz zu den christlichen Feiertagen treten solite. Dazu gehörten vor allem der Jahrestag der Machtergreifung, der Heldengedenktag, Führergeburtstag, Reichsparteitag und die Sommersonnenwende. Longerich: Nationalsozialistische Propaganda, S. 308.

${ }^{335}$ Klönne: Jugend im Dritten Reich, S. 239.

${ }^{336}$ Ebd., S. 227. 
Es ist auffallend, dass der Romancier keine älteren Menschen schildert, die so wie die jungen mit dem ganzen Herzen der NS-Ideologie verfallen wären. Sogar der bereits genannte Dr. Mayerhofer, der eine Studentenversammlung anlässlich einer Sonnwendfeier führte, war kein überzeugter Nationalsozialist, wie sich im Nachhinein herausstellte. Man warf ihm vor, gegen Deutschland gehetzt und Hitler geschmäht zu haben. Deshalb wurde er nach Dachau gebracht. (TV, S. 109)

Dass in Totale Verdunkelung speziell Frauen vom Nationalsozialismus besonders angetan sind, soll auch nicht wundern. „Von Frauen ist Hitler entdeckt worden. [...] Im Kampf um die Macht waren es die Frauen, die mit ihrer Stimmabgabe Hitler schließlich so hoch emportrugen. "337 Dabei hat sich die „größere Anfälligkeit der Frauen für die vorurteilsträchtigen Parolen des Dritten Reiches"338 bis in die Schlussphase des Zweites Krieges gehalten. Auch in den letzten freien Wahlen Anfang der dreißiger Jahre stimmten Millionen deutscher Frauen für eine, gemessen am modernen Verständnis, extrem frauenfeindliche Partei. ${ }^{339}$ Elisabeth Klamper erklärt diesen Zustand damit, dass eine derart große Identifikation vieler Frauen mit dem politischen System durch „Vorspiegelung einer gesellschaftlichen Aufwertung der Hausarbeit durch die NS-Propaganda“" ${ }^{\text {340 }}$ zustande kam.

Zusammenfassend könnte man sagen, dass auch die Darstellung von Schicksalen junger Menschen in der NS-Zeit im Allgemeinen den historischen Fakten entspricht. Was im Roman fehlt und in den Artikeln über die Frauen in der NS-Zeit betont wird, ist diese sich im Laufe des Krieges verändernde Einstellung zur Aufgabe der Frau von der "Huiterin des Haushalts“ und Mutter möglichst vieler Kinder bis zum Einsatz der Frauen in den Fabriken. Bei Vogel nämlich taucht keine einzige Frau auf, die irgendwo in einem Rüstungsbetrieb tätig

${ }^{337}$ Rauschning, Hermann: Gespräche mit Hitler, Wien 1973, S. 240, zitiert nach: Dusek, Pelinka, Weinzierl: Zeitgeschichte im Aufriß, S. 138.

${ }^{338} \mathrm{Ebd}$.

${ }^{339}$ Thalmann, Rita, R.: Zwischen Mutterkreuz und Rüstungsbetrieb: Zur Rolle der Frau im Dritten Reich. In: Deutschland 1933-1945, S. 189-217, hier S. 200.

${ }^{340}$ Klamper, Elisabeth: Vom „wesensgemäßen“ Einsatz der deutschen Frau. In: Wien 1938. Wien: Historisches Museum der Stadt Wien 1988, S. 343356. Zitat S. 345. 
wäre. Dafür gibt es einige Rot-Kreuz-Schwestern und Büroangestellte.

\section{Antisemitismus und Judenvernichtung}

Dieses Problem wird in Totale Verdunkelung grundsätzlich an drei Stellen angesprochen: Erstens in den Erinnerungen Richard Wohllebens an das Jahr 1938 (eine Schmier- und Plünderungsaktion der Hitlerjugend), zweitens in der Darstellung des Schicksals der „Mischehe" Steffis und Herberts und drittens in der für die Entwicklung des Helden relevanten Begegnung mit einer alten Jüdin.

Das Wissen oder das Nicht-Wissen um die Existenz von Konzentrationslagern

Richard Wohlleben, der in Totale Verdunkelung im Luftgaukommando eine hohe Stelle bekleidet, trifft während eines Bombenanschlags auf dem Weg zum Schutzraum eine alte Frau, die sich weigert, in den Schutzraum zu gehen. Er errät schnell den Grund ihres Zögerns und rettet ihr das Leben, indem er ihr ein Medikament hinreicht und sie in ihr Versteck begleitet. Eine Jüdin, die sich mit Hilfe ihrer Freunde als ein so genanntes „U-Boot" fast den ganzen Krieg verstecken konnte, geht, gestuitzt durch den Arm eines Oberleutnants der Luftwaffe, durch das von einem Bombenanschlag zerstörte Wien. Von ihr erfährt Richard von den Massenvernichtungen in den Konzentrationslagern:

[...]hier in dieser schmalen Kammer erfuhr er es zum ersten Mal: Man brachte sie nicht ganz einfach in ein Konzentrationslager, wo sie für Kriegsdauer interniert gehalten wurden, man sperrte sie nicht in ein Getto, wo sie schlecht versorgt und von der Außenwelt abgeschnitten sich gegenseitig peinigten, man steckte sie nicht in ein Arbeitslager, wo sie an Unterernährung und Strapazen langsam zugrunde gingen, man stellte sie nicht mehr vor ein Gericht, nicht einmal mehr vor ein Volksgericht, ja man stellte sie nicht einmal vor ein Peloton. Man vergaste sie wie Ungeziefer zu Tausenden in eigens dafür eingerichteten Anstalten. (TV, S. 173)

Als er das Versteck der jüdischen Malerin verlässt, spürt er überall den Brandgeruch und meint, dass dies die Vergeltung für den Massenmord an den Juden sei. „Der Brandgeruch der Krematorien. Wir haben sie vergast und verbrannt, und nun werden wir verbrannt." 
(TV, S. 174) Trotzdem hofft er, dass es nicht wahr ist. „Doch er konnte es noch nicht glauben. Da war irgendwo ein Funke Zweifel in ihm, ein Funke Hoffnung war, dass es nicht so sei, dass es nur eine Ausgeburt der gequälten und verfolgten Menschen sei, die solche grauenhaften Bilder beschworen." (TV, S. 174) Wohlleben wird erneut mit der Jüdin konfrontiert, als diesmal er bei ihr Hilfe sucht, nachdem er auf der Flucht vor der SS einen jungen SS-Mann erschossen hat. Er wird vor allem wegen des jungen Alters dieses SSManns von Gewissensbissen gequält. Die Jüdin zeigt kein Mitleid für diesen Menschen. Sie ist sich sicher, dass der erschossene junge Mensch seine Taten nicht bereuen würde, im Gegenteil, er würde bereuen, dass er nicht noch mehr Menschen umgebracht habe. Wohlleben versucht solche jungen Menschen zu verteidigen und bringt das Gespräch in einen biblischen Kontext, ${ }^{341}$ indem er die Worte des gekreuzigten Jesus im Zusammenhang mit diesem jungen, von der Nazipropaganda verblendeten Menschen ausspricht und behauptet, dass sie nicht wüssten, was sie täten. Die Jüdin, die besser als Richard in der Bibel bewandert ist, sagt, dass diesem Spruch noch der Satz: „Vater, verzeih ihnen!“342 vorangestellt sei. Damit spricht sie das Thema der Vergebung der Sünden an und stellt fest, dass die Voraussetzung dazu die Reue sei, die dieser junge tote SS-Mann und ihm Ähnliche sicher nie zeigen würden. Sie klagt die Passivität der Gesellschaft an, die zur Tragödie der jüdischen Mitbürger geführt habe: „Sie haben sich einverstanden erklärt, daß man uns umbringt!“ (TV, S. 188), wirft sie ihm vor. Sie zweifelt daran, dass man nicht gewusst hat, dass das jüdische Volk vernichtet wird. Darauf versucht Wohlleben, ihr die Situation der meisten Menschen verständlich zu

${ }^{341}$ indirekte biblische Zitate oder Andeutungen auf christliche Glaubensinhalte sind bei Vogel ziemlich oft anzutreffen, was der Autor selber zugibt, s. Interview mit Alois Vogel im Anhang. Vgl. auch z.B. die Erzählungen Unkeuschheit und Standgericht. In: AV: Jahr und Tag Pohanka und 11 Erzählungen, hrsg. v. August Obermayer und Wendelin SchmidtDengler. Wien, München: Deuticke $2000(=3$. Band der Werkausgabe), S. 283-300 oder Das Fischgericht und Die Morgengabe In: AV: Das Fischgericht. Tagtraumerzählungen. Wien, München: Jugend und Volk 1982, S. entsprechend 18-31 u. 32-43, um nur einige zu nennen.

${ }^{342}$ Das Evangelium nach Lukas, Die Kreuzigung: 23, 26-34. In: Die Bibel in der Einheitsübersetzung der Heiligen Schrift, hrsg. v. Interdiözesanen Katechetischen Fonds. Klosterneuburg: Österreichisches Katholisches Bibelwerk 1986, S. 1178. 
machen. Inzwischen wird er sich aber bewusst, dass diese tatsächlich keineswegs verständlich war:

Man hatte den Juden ihre Geschäfte genommen, sie aus allen Berufsverbänden ausgeschlossen, sie jeder Arbeitsmöglichkeit beraubt und letzten Endes jene, die trotz allem nicht ins Ausland gingen, nach dem Osten deportiert. Man sprach davon, in Polen, woher ja - bekanntlich - alle Juden gekommen waren, werden sie in einem Territorium zusammengesperrt. Angesiedelt. Dort können sie sich gegenseitig begaunern und betrügen. [...] Und schließlich waren sie ja doch Juden, etwas anderes als wir. Und wahrscheinlich - so sagte man sich - hatten sie auch selbst irgendwie Schuld an ihrem Schicksal. Immer schon anders wollten sie sein, erwähltes Volk, Besser-sein-Wollen als die anderen Völker. (TV, S. 188)

Man kann hier sehen, wie klischeehaft Richards Denken über Juden war. Bedenkenlos wiederholt er stereotype Meinungen. Das dem Schicksal der Juden gegenüber gleichgültige Verhalten der ,arischen“ Bevölkerung erklärt er damit, dass sich während des Krieges niemand mehr Gedanken über verschwundene Juden gemacht habe, da man mit eigenen Sorgen beschäftigt gewesen sei. Der deutsche Soldat beteuert, dass die Mehrheit der Bevölkerung nichts von der Massenvernichtung gewusst habe. Eine solche Entschuldigung stellt die Jïdin jedoch nicht zufrieden, sie behauptet, dass man nur Mein Kampf zu lesen bräuchte, um zu wissen, was man zu erwarten hatte. Wohlleben ist sehr verwundert über diese Tatsache, dass ausgerechnet sie die "Bibel“ der Nationalsozialisten kennt. Auf ihre weiteren Anklagen hin setzt Richard seine Erklärungen fort: „Man denkt nicht darüber nach. Jeder denkt zuerst an sich, an seine nächsten Angehörigen, und erst wenn einer, so wie ich jetzt, jemandem wie Sie gegenübergestellt und mit dessen Schicksal konfrontiert wird, beginnt er weiter zu denken." (TV, S. 189) Als dies der Jüdin aber immer noch nicht überzeugend genug scheint, gibt Richard endlich zu: ,[...]sagen wir es ehrlich. Wir haben nichts gewußt, weil wir nichts wissen wollten, [Hervorhebung - E.M.F.] weil uns, wie alle Menschen zu allen Zeiten, nur das zu einer Reaktion herausfordert, was uns selber betrifft, was jeder am eigenen Leib erlebt." (TV, S. 190)

Diese Stelle wurde so ausfuhrlich zitiert, weil sie aus zweierlei Gründen eine der Schlüsselstellen des Romans zu sein scheint. Erstens stellt sie den Höhepunkt in der Entwicklung der Gestalt Richard Wohllebens dar. Das Treffen mit der alten Jüdin verstärkt in ihm die Überzeugung, dass er persönlich mehr gegen das Hitlerregime unter- 
nehmen muss und dazu vielleicht auch mit den Menschen, die 1934 im gegnerischen Lager waren, zusammenarbeiten soll. Zweitens berührt sie das heikle Thema der Verantwortung dem jüdischen Volk gegenüber und die Frage, ob man von der Massenvernichtung der Juden in den Konzentrationslagern gewusst hat. Die Gestalt der alten Jüdin, die dank ihren Freunden den Krieg überlebt hat, soll das Gewissen vieler „Mitläufer” des NS-Regimes ansprechen. Sie und ihre Bilder - denn sie ist Malerin - klagen ausgerechnet die "gewöhnlichen Menschen" wie Richard Wohlleben an (den man trotz seiner Position in der Luftwaffe auf keinen Fall als überzeugten Nazi bezeichnen kann), die das Unrecht, das ihren jüdischen Mitbürgern angetan wurde, sahen und duldeten. Einerseits wird im Roman die Überzeugung vermittelt, dass man gemeinhin nichts von der so genannten „Endlösung der Judenfrage” wusste. Andererseits wird diese Einstellung durch eine Art von Rechtfertigung gebrochen, die sich eigentlich als Anklage entpuppt. Der Satz „Wir haben nichts gewußt, weil wir nichts wissen wollten" besagt mehr als nur die Feststellung, dass man passiv war, er bedeutet das aktive und bewusste oder teilweise bewusste Verdrängen dieser Tatsachen. Er drückt die Absicht aus, nichts zu sehen, wegzuschauen. Im Gegensatz zu Richard Wohlleben, der sich während des ganzen Krieges in Wien aufhielt, wusste sein Vorgesetzter, Oberstleutnant Perkal, von der Existenz der Konzentrationslager, denn er bestätigt seinem Mitarbeiter die Version der alten Jüdin. (TV, S. 180)

Diese Darstellung entspricht den Auffassungen der Wissenschaftler. „Die industrielle Massentötung blieb der Wahrnehmung der Österreicher verborgen,"343 schreibt Ernst Hanisch. „In den breiten Bevölkerungsschichten in der Heimat wußte man nichts über dieses Morden, das jede menschliche Vorstellungskraft uiberstieg," 344 wird in einem Aufsatz festgestellt. Andererseits lässt sich trotzdem nicht verneinen, dass zumindest manche Soldaten vom Völkermord gewusst haben müssen. Steinert weist darauf hin, dass dieses Wissen zuerst auf die obersten politischen, zum Teil auch militärischen Führungsorgane sowie auf die beteiligten Verwaltungen und Ausführenden beschränkt war, sich aber im Laufe der Zeit durch Beobachtungen und manchmal auch durch Teilnahme auf die breiteren Wehrmachtskreise ausbreitete. ${ }^{345}$ Gerhard Botz hebt hervor, dass nicht genau

\footnotetext{
${ }^{343}$ Hanisch: Der lange Schatten des Staates, S. 383.

${ }^{344}$ Steinert: Deutsche im Krieg, S. 485. ${ }^{345}$ Ebd.
} 
bekannt war, was sich in dem fernen Polen ereignete. „Man konnte daruiber in Österreich hinwegsehen und brauchte sich nicht beunruhigen lassen. " ${ }^{646}$ Dies war durch die Entziehung von unmittelbaren Wahrnehmungen, die vollkommene Anonymisierung der Opfer und eine räumliche, soziale und emotionale Trennung der Befehlsgeber und -ausführer vom Leid und Schmerz der zu Vernichtenden möglich.

\section{November 1938}

An die Schmier- und Plünderungsaktion der Hitlerjugend im November 1938, deren Zeuge Richard nach dem „Anschluss“ Österreichs an das Dritte Reich wurde, erinnert er sich erst unter dem Eindruck des Treffens mit der jüdischen Malerin. Diese Sequenz gehört inhaltlich eigentlich dieser zufälligen Begegnung an, wegen ihrer zeitlichen Distanz aber - sie wird als eine Rückblende eingesetzt - und ihrer Bedeutung für das Thema Judenverfolgung, ist sie einer Sonderbesprechung wert. Diese Erinnerung wird aus den tiefen Ebenen seines Bewusstseins hervorgeholt. Er hat sie verdrängt, da er damals nichts gegen dieses Unrecht unternahm, obwohl er sich in jenem Augenblick dessen bewusst war, es für eine Gemeinheit hielt und darüber entsetzt war. Auch handelte es sich um einen Konfektionsladen, den der ihm seit Jahren bekannte Mayer geführt hatte. In seinem Geschäft hatte ihm seine Mutter seinen ersten Anzug gekauft.

Hitler-Jugend stand vor einigen Geschäften, die noch Juden gehörten. Bei manchen waren die Fensterscheiben zertrümmert und die Regale ausgeräumt. Bei Mayer, wo er seine Anzüge kaufte, hielten zwei Halbwüchsige den Besitzer unter dem Gejohle und der aufmunternden Assistenz von zehn bis fünfzehn jüngeren Burschen dazu an, mit Kalkfarbe [...] auf die noch heilen Scheiben der Auslagen: JUD und SAUJUD zu pinseln. Mayers Augen waren verschwollen, das Lid des rechten war blaurot unterlaufen, seine Kleidung war schmutzig. Der Mann zitterte am ganzen Leib. Einer der beiden Anführer [...] hatte eine Pistole in der Hand, der andere einen Hartgummiknüppel. Der mit dem Knüppel schrie: „Die Sara,

${ }^{346}$ Botz, Gerhard: Die Ausgliederung der Juden aus der Gesellschaft. Das Ende des Wiener Judentums unter der NS-Herrschaft (1938-1943). In: Eine zerstörte Kultur. Jüdisches Leben und Antisemitismus in Wien seit dem 19. Jahrhundert, hrsg. v. Gerhard Botz, Ivar Oxaal, Michael Pollak. Buchloe: Obermayer 1990, S. 285-311. Zitat S. 306. 
wo ist die Sara! Die Sara muß her! Wir werden ihr den Judenstern auf den dicken Arsch tätowieren!" Die jüngeren Burschen lachten daraufhin und schrien im Sprechchor: „Sara! Sara! Sara!“ (TV, S. 169)

Die Reaktionen der Passanten waren unterschiedlich und reichten von Akzeptanz über Aufhetzung (,Geschieht ihnen schon recht. [...] Diese jüdischen Blutsauger. Man weiß doch, welche Schinderlöhne die zahlen. Können leicht billiger sein als unsere arischen Kaufleute, wo sie unsere braven Mädln ausbeuten. Für ein Butterbrot müssen sie arbeiten. $\mathrm{Na}$, und der junge Chef nimmt sie natürlich ins Bett. [...] Höchste Zeit, daß man einmal ein End' damit macht.“, TV, S. 169f.) bis hin zur Ablehnung. Eine ältere Frau protestierte und nahm Mayer in Schutz. Sie sagte, dass es auch unter den Juden anständige Menschen gebe. Nur einer der Zuschauer - ein junger Chorherr - wagte es, die randalierenden Jungen anzusprechen. Dann löste sich die Menge auf. Richard machte sich Vorwürfe, dass er dem alten Mayer nicht geholfen hatte.

Wahrscheinlich handelt es sich an dieser Stelle um die „Reichskristallnacht". vom 9.-10. November, da im Text der Name Ernst vom Rath genannt wird, der Botschaftssekretär in der deutschen Botschaft in Paris war. Er starb an den Folgen eines von Herschel Grynszpan verübten Attentats. Dies entfesselte den gegen die Juden gerichteten Terror. ${ }^{347}$

Nach offiziellem Wunsch waren diese Ausschreitungen als Ausdruck der „spontanen Volkswut“ nur von Zivilisten durchzuführen, niemand in Uniform sollte sich daran beteiligen. Das rohe Vorgehen der Hitlerjugend, das auch in Vogels Schilderung zum Ausdruck kommt, wurde danach offiziell gerügt. ${ }^{348}$ Wiener Nationalsozialisten sollen Ablehnung und Erschütterung gezeigt haben über die Tatsache, dass bei der Durchführung der „Aktion“ Skandalszenen vorgefallen sind, die das Ansehen der Partei und des Reichs aufs schwerste schädigen würden. ${ }^{349}$

Sicherlich ist es auch kein Zufall, dass ausgerechnet ein Chorherr Vertreter des Klerus - dem jüdischen Händler Hilfe leistet. Damit ist die Rolle der Kirche im Widerstand gegen den Nationalsozialismus angedeutet. Diese Hypothese wird auch durch die Tatsache bestätigt,

${ }^{347}$ Kleindel: Österreich, S. 368.

${ }^{348}$ Ackerl: Die Chronik Wiens, S. 408.

${ }^{349}$ Botz: Die Ausgliederung, S. 298. 
dass in Wohllebens Erinnerung an die Augustinerstraße, in die er nach dem Bombenangriff zuruickkehren will, der Augustiner Chorherr auftaucht. Es könnte eine Anspielung auf einen Klosterneuburger Chorherrn, den ehemaligen Angehörigen der SA, Karl Roman Scholz sein, um den sich bereits im April 1940 Widerstandsgruppen formierten. $^{350}$

\section{Die Geschichte einer ,Mischehe“"}

Als Poldis Kollegin Steffi schwanger wurde, beschlossen sie und ihr Partner zu heiraten, obwohl sie ahnten, dass es um ihre Zukunft nicht gut steht, da man bei der Ermittlung des Ariernachweises entdeckt hatte, dass Herbert Vierteljude ist. Sofort hat man ihn aus den Reihen der SA ausgeschlossen. (TV, S. 32) Steffi enttäuscht ihre Freundinnen mit ihrer Entscheidung, dass sie die Informationen über die Vererbungslehre Mendels, die ihnen bei den von NS-Frauenorganisationen veranstalteten Heimabenden vermittelt wurden, mit der Wirklichkeit nicht in Einklang bringen wird. Trotzdem besuchen sie Steffi heimlich und bringen ihr verschiedene Lebensmittel. Allerdings ist Poldi die einzige, die ihre eigenen Lebensmittelkarten mit der Freundin teilt. In ihrem nächsten Umfeld wird diese junge Frau verschiedenen Repressalien ausgesetzt, von einer Nachbarin wird sie regelrecht angeprangert. Ihr Mann war am Ladogasee, wo er verwundet wurde und so ein Bein verloren hatte. Er nahm am Krieg an der Ostfront teil. Trotz der schwierigen materiellen Lage nimmt das Paar später, jetzt bereits mit zwei eigenen Kindern, noch ein Kind auf. Es ist die Tochter einer Frau, deren Mann vorgeworfen wurde, Hochverrat durch so genannte „Wehrkraftzersetzung“ betrieben zu haben. Vorsichtshalber sagen sie ihren Nachbarn nicht die Wahrheit. Sie halten es für die beste Lösung, ihnen zu sagen, dass der Vater des Mädchens gefallen und die Mutter kriegsdienstverpflichtet sei. (TV, S. 148)

Fazit: Alois Vogel zeichnet in den geschilderten Szenen und Gesprächen - wenn auch nicht chronologisch und nur umrisshaft fast alle Phasen der Judenverfolgung nach. Im Allgemeinen entsprechen sie dem von Gerhard Botz ausgearbeiteten Schema der Juden-

${ }^{350}$ Ackerl: Die Chronik Wiens, S. 412 . Vgl. auch Dusek, Pelinka, Weinzierl: Zeitgeschichte im Aufriß, S. 247; Botz, Gerhard: Nationalsozialismus in Wien. Machtübernahme und Herrschaftssicherung 1938/39. Buchloe: dvo 1988 (3. Auflage), S. 353f. 
verfolgung in acht Stufen. ${ }^{351}$ Es ist hier nicht der richtige Ort, um ins Detail zu gehen, doch soll auf manche Parallelen hingewiesen werden.

In der Phase, die Botz als „,begriffliche Ausgrenzung der Feindgruppe" (2. Stufe) bezeichnet, treten die Nürnberger Rassengesetzte in Kraft (20. Mai 1938). Die „Ahnenforschung“ wird intensiv betrieben, bald weiß fast jeder, ob er unter diese Definition von „Jude“" fällt oder nicht. Jeder Staatsbürger war davon betroffen und musste vor unliebsamen Entdeckungen zittern. So auch Herbert, der Mann Steffis in Totale Verdunkelung. Da er nur „Vierteljude“ war, wurde er nicht deportiert, auch haben ihn die Ehe mit einer "Arierin“ und die Kinder geschützt. ${ }^{352}$ Nicht zufällig rufen die randalierenden Hitlerjungen Frau Mayer „Sara“. Seit Juli und August 1938 haben Bestimmungen gegolten, nach denen alle Juden die Vornamen „Israel" oder "Sara" annehmen mussten. ${ }^{353}$ Die Tatsache, dass Richard Wohlleben im März 1945 einer älteren Jüdin begegnet, hat ebenfalls ihre historische Begründung. In der Zeit vor den Deportationen waren vierzig Prozent der Wiener Juden älter als 60 Jahre, der Anteil der unter 40jährigen betrug gerade 19 Prozent. Überdies waren Frauen darunter im Verhältnis 1:2 iberrepräsentiert. ${ }^{354}$ Angesichts der Überalterung und des Frauenüberschusses kann es nicht verwundern, dass der Romancier sich gerade der Gestalt einer alten Jüdin bedient, um die Tragödie der Juden anschaulich zu machen. Die Realisierung des NS-Stereotyps vom „Juden“ (7. Stufe bei Botz) nimmt bei Vogel eine beachtliche Stellung ein, was besonders bei der Schilderung der Ausschließung der Juden aus dem kulturellen Leben der Fall ist. Die Einstellung Richards zur Situation der Juden vor dem Krieg und während des Kriegs, die in seinem Unterbewusstsein tief verankert war und die er ohne das Treffen mit der Jüdin nicht zum Ausdruck

${ }^{351}$ Botz: Die Ausgliederung. Vgl. auch: Moser, Jonny: Die Apokalypse der Wiener Juden. In: Wien 1938. Wien: Historisches Museum der Stadt Wien 1988, S. 287-297.

${ }^{352}$ Rosenkranz weist darauf hin, dass Juden oder „Halbjuden”, die in ,privilegierter" Mischehe lebten, unter bestimmten Umständen von der Deportation ausgenommen waren, so wenn sie Kinder mit einem nichtjüdischen Partner hatten. s. Rosenkranz, Herbert: Verfolgung und Selbstbehauptung. Die Juden in Österreich 1938-1945. Wien 1978. Zitiert nach Botz: Die Ausgliederung, S. 402.

${ }^{353}$ s. Botz: Die Ausgliederung, S. 305.

${ }^{354} \mathrm{Ebd}$. 
gebracht hätte, gleicht der letzten Phase von Botz, die er „Abschiebung aus dem Wahrnehmungsfeld und Vernichtung" nennt.

Andere Stufen wie Zerstörung der wirtschaftlichen Subsistenz (3. Stufe), erzwungene Emigration (4. Stufe), räumliche A bsonderung (6. Stufe) werden eigentlich nur im Gespräch Richards mit der jüdischen Malerin angesprochen.

\section{Widerstand}

In Totale Verdunkelung werden viele Widerstandsformen aufgezeigt. Sie reichen von individuellen Widerstandshandlungen bis zum organisierten Widerstand. Individuelle Widerstandshandlungen werden meist von Franz Prannowitz durchgeführt. Das sind in der Regel unerlaubte Äußerungen, Gesten und Handlungen, die er eher aus Trotz als aus innerer Überzeugung vollführt. Im Laufe der Monate, die er in Wien verbringt, engagiert er sich jedoch immer mehr für aktivere und bewusstere Formen des Widerstands. Er beurteilt das herrschende Regime negativ und erlaubt sich beispielsweise in Anwesenheit vieler Menschen in einem Luftschutzraum den Krieg als „beschissen“ zu bezeichnen (TV, S. 97). Oft sind seine Äußerungen kontextgebunden und nicht für jeden verständlich. So sagt er beispielsweise, dass sich alle viel ersparen hätten können und meint damit natürlich den Krieg; kurz darauf, als jemand sich über die sich ständig wiederholenden Bombenangriffe beklagt, bemerkt er zynisch, dass der Krieg eine „wahrhaft große Zeit" (TV, S. 100) sei. Seine Anspielungen sind besonders Poldi Mihatsch nicht verständlich. Am Anfang ihrer Bekanntschaft sprechen sie noch oft von Politik und haben meistens völlig unterschiedliche Meinungen, je besser sie einander jedoch kennen lernen - sie beginnen ein Liebesverhältnis - desto weniger denkt das Mädchen über den Sinn der von ihrem Geliebten ausgesprochenen Worte nach. Als der Krieg schon fast zu Ende geht und die Russen vor Budapest stehen, bemuiht Franz ein Sprichwort: „besser ein Ende mit Schrecken als ein Schrecken ohne Ende." (TV, S. 147) Seine unwillige Haltung dem Hitlerregime gegenüber zeigt sich auch darin, dass er das Hitlerbild, das er in Poldis Wohnung findet, zudeckt (TV, S. 124) und beim Hitlergruß den Arm kaum in die Höhe bringt. ${ }^{355}$

${ }^{355}$ Den „Deutschen Gruß” verwenden im Roman weder Franz Prannowitz' Parteifreund Groß noch die Frau des Oberstleutnants Perkal. Die Verweigerung des Deutschen Grußes galt nach dem sogenannten „Heimtückegesetz" als Delikt, s. Neugebauer, Wolfgang: Widerstand und Opposition. 
(TV, S. 80) Zu Zeiten seines Einsatzes hatte er oft mit Hilfe der Bordfunkgeräte den englischen Sender abgehört. (TV, S. 151) Der zum Feldwebel beförderte Flugzeugführer ignoriert die NS-Vorschriften und gibt den russischen Fremdarbeitern und Kriegsgefangenen wiederholt Zigaretten, dabei kümmert er sich nicht darum, dass ihn jemand dabei sehen und denunzieren könnte. Auf die empörte Reaktion Poldis, die eine solche Szene beobachtet und ihn belehrt, dass dies verboten sei, erwidert er: „Das haben schließlich nur Menschen verboten, und ich bin auch ein Mensch, und ich erlaube es mir" (TV, S. 29), an einer anderen Stelle denkt er "sie konnten ihn mit diesen Hinterlandsvorschriften am Arsch lecken." (TV, S. 87)

Der erste Ansatz zu einer bewussteren Widerstandshaltung ergibt sich für Franz durch die erneute Begegnung mit Richard Wohlleben, der jetzt, nach zehn Jahren, sein Vorgesetzter ist. Im Luftgaukommando gesteht Prannowitz, dass er zwar immer das Ende des Krieges gewünscht, jedoch nichts dazu beigetragen habe. Trotzdem ist er überzeugt, dass der Widerstand sinnlos ist: „Alle sind wir eingespannt, jeder; ob er will oder nicht, ja, auch dann, wenn er nicht will, arbeitet für dieses System." (TV, S. 75) Als Wohlleben ihn fragt, ob er noch Kontakte mit seinen alten Parteifreunden habe, wird er misstrauisch und erwidert, er habe keine Verbindungen mehr, denn sein bester Freund sei einige Wochen nach dem Anschluss verhaftet und noch vor dem Kriegsbeginn ermordet worden, andere seien verschwunden, die übrigen seien an die Front gegangen. Daher scheitert der erste Versuch Richard Wohllebens, Franz Prannowitz zum Widerstand anzuregen. Als Franz aber zufällig einen seiner Parteifreunde trifft, wird er langsam in eine Hilfsaktion für die Frau eines Justifizierten und ihre Kinder involviert. Von Groß erfährt er, dass am Laaer Berg vierzehn Männer ausgehoben wurden, die insgesamt drei Witwen und sieben unversorgte Kinder hinterlassen hätten. (TV, S. 91) Am schlimmsten sei es bei einer der Witwen, die drei Kinder habe. Auf dem Laaer Berg habe man nämlich eine geheime Druckerei eingerichtet und Flugzettel mit Aufforderungen zur Desertion und Sabotage hergestellt. Den Männern habe man Hochverrat und Wehrkraftzersetzung vorgeworfen, sie vor das Volksgericht gestellt und hingerichtet.

In: NS-Herrschaft in Österreich 1938-1945, hrsg. v. Emmerich Talos, Ernst Hanisch, Wolfgang Neugebauer. Wien: Verlag für Gesellschaftskritik 1988, S. 537-552, hier S. 548. 
Franz hilft seinem Chef Wohlleben, indem er einem Mädchen aus seiner Abteilung am Bahnhof einen insgeheim geänderten Marschbefehl übergibt und es dann zu einem anderen Zug begleitet. Die junge Luftwaffenangestellte Inge Grazl hatte einigen russischen Kriegsgefangenen ein paar Lebensmittel zugesteckt, worauf die Todesstrafe stand. Dessen war sich dieses junge, aus reiner Nächstenliebe handelnde Mädchen nicht bewusst. Richards Vorgesetzter, Oberstleutnant Perkal, beauftragt ihn, dem Mädchen zu helfen und ihr einen geänderten Marschbefehl zu schreiben. Offiziell hätte die ahnungslose junge Frau nach Brünn fahren sollen, während sie sich tatsächlich nach Verona, zu Hauptmann Ettenreich, der an der Verschwörung am 20. Juli 1944 teilgenommen hatte, begeben hat (TV, S. 111). Unterdessen wurde Gretl Liebeneder, die Franz noch als Gretl Dvořak gekannt hat, festgenommen und ins Landesgericht gebracht. Jetzt wendet sich Franz an Richard, da er für Liebeneder gefälschte Dokumente benötigt, damit sie verschwinden kann. Prannowitz erlebt eine Art von innerer Verwandlung, er kommt zu dem Schluss, dass er diesem Regime gegenüber nicht mehr passiv bleiben kann: „Lange geglaubt, mich wegheben zu können aus diesen Zusammenhängen, außerhalb des Geschehens zu sein, weil ich Hunderte oder Tausende Meter über der Erde, auf der dieses Geschehen stattfindet, schwebte. Es entkommt aber keiner." (TV, S. 141) Trotzdem ist er noch nicht zur Zusammenarbeit mit Wohlleben bereit, denn er kann die Schranken von zehn Jahren nicht überbrücken und reagiert auf die Worte seines Vorgesetzten mit Ablehnung: „Zusammenarbeiten, zusammenarbeiten. Er wollte mit niemandem zusammenarbeiten. Er haßte zwar dieses Regime und war von seinem baldigen Untergang überzeugt, aber zusammenarbeiten?" (TV, S. 142) Als Franz fast am Ende des Romans vom angeblichen „Heldentod“ Richards erfährt, ruft er sich eine Szene aus dem Jahr 1934 ins Gedächtnis zurück, als er ihm die Nachricht vom Tode seiner Schwester Leni überbracht hat. Bevor Franz ihm diese Information mitteilen konnte, hat Richard gesagt, dass Lenis Mann jetzt keine Angst mehr zu haben brauche, da man ihn jetzt höchstens einsperren werde. Dieser Satz hatte sie durch alle diese Jahre wie eine dünne Wand getrennt. Im Angesicht des Todes von Wohlleben in den letzten Tages des Zweiten Weltkrieges bedauert Franz, dass er im Herbst 1944 seinem Chef nicht mehr entgegengekommen war. Die völlige Veränderung Franzens zeichnet sich im Gespräch mit Herbert ab, der die Meinung vertritt, dass die Politik die Sache der Großen sei und der Durchschnittsbürger sowieso keinen 
Einfluss auf das politische Geschehen habe. Deshalb hätten sämtliche Bemühungen von vornherein keinen Sinn. Auf solche Aussagen reagiert Franz mit Empörung und spricht sich entschieden für die Verantwortung des Einzelnen in jeder Situation aus, auch in einer solch extremen wie der des Krieges. Dazu verwendet er einen bildlichen Vergleich, der ins Pathetische umschlägt:

Das ist es eben, jeder redet sich aus, daß er als kleines Rädchen nichts tun kann, nichts ändern kann, und doch ist das nicht wahr. Das kleinste Rädchen ist wichtig, und wenn es nicht so läuft, wie es sich der Maschinist vorstellt, können sich auch die großen Räder nicht bewegen. Zwölf Männer haben von Palästina aus die ganze Welt verändert. Auch wir können es, wenn wir wollen. (TV, S. 155)

Noch kurz zuvor, beim ersten Treffen mit Wohlleben nach 1939, als dieser ihn davon überzeugen wollte, dass der Widerstand des Einzelnen für den Ausgang des Krieges von enormer Bedeutung sei, wollte er das nicht glauben. Am Ende des Romans, als die beiden einander in der Feuerwehrzentrale Am Hof treffen, wo sie unterzutauchen versuchen, scheinen die Unterschiede, die durch ihre weltanschauliche Haltung im Jahr 1934 entstanden sind, endgültig überwunden zu sein.

Beide hatten bereits einige Jahre früher versucht, ihre Bekanntschaft zu intensivieren, um gemeinsam gegen das NS-Regime zu agieren. Während ihres Treffens im Jahre 1944 erinnern sich beide an ihre Begegnung in einem Weinkeller kurz vor Kriegsausbruch. Damals wurden sie von der Marschmusik und von einem Spitzel gestört. Ein noch größeres Hindernis waren ihr gegenseitiges Misstrauen und die Vorurteile, die sie nicht überwinden konnten. Der Sozialist, der zehn Jahre arbeitslos gewesen war, konnte dem ehemaligen Heimwehrmann, dessen Bruder Blutordensträger war, nicht glauben. Richard erschien es dagegen sinnlos, mit Franz über andere Dinge zu sprechen als von belanglosen Sachen wie zum Beispiel sein Motorrad, das sich der langjährige Arbeitslose jetzt leisten konnte.

In den letzten Monaten des Krieges werden Franz und Richard vom Sicherheitsdienst und von der SS gesucht, vor allem wegen Inge Grazl, nach der bereits gefahndet wird. Außerdem ist die Gestapo einer geheimen Druckerei auf der Spur. Franz hat in den Vorschlag Richards eingewilligt, als Setzer in einer Druckerei zu arbeiten. In dieser Werkstatt in Klosterneuburg werden unter dem Deckmantel der Produktion von liturgischen Texten Flugschriften für russische Kriegsgefangene und Druckwerke mit Aufforderung zur Sabotage an- 
gefertigt. Das Werk wird von Dr. Mayerhofer, einem Aktivisten einer nationalsozialistisch eingestellten Studentengruppe aus dem Jahr 1938, geführt, der als ehemaliger KZ-Häftling besonders unter die Lupe genommen wird.

Das sich im Laufe der Handlung verändernde Verhältnis Franzens zum Widerstand und damit seine menschliche Entwicklung stehen im Mittelpunkt dieses Romans. Franz verwandelt sich von einem dem NS-Regime zwar abgeneigten, aber passiven Menschen zum aktiven Bürger, der unter Einsatz seines Lebens den Opfern des Nationalsozialismus hilft. Diese Opfer sind in Totale Verdunkelung das junge Mädchen Inge Grazl, das den russischen Kriegsgefangenen ein paar Lebensmittel zusteckt, sowie die Frau und drei Kinder eines für die Wehrkraftzersetzung hingerichteten Sozialisten.

Die Entwicklung der Figur Richard Wohllebens ist nicht so deutlich und leicht zu verfolgen wie die Franz Prannowitz'. Diese Tatsache ist darauf zuruickzuführen, dass Franz ein Außenseiter ist, der quasi aus einer anderen Welt kommt, wo er als Pilot keine direkte Beriihrung mit dem durch den Krieg verursachten Leid hat, obwohl man ihn eigentlich als Verursacher dieses Leids bezeichnen könnte. Er hat unter anderem Bomben auf London und La Valetta auf Malta abgeworfen, er nahm an den Kämpfen um Tobruk und Stalingrad teil. Seine Konfrontation mit dem Kriegsgeschehen im Hinterland, das ihm unbekannt war, ist daher deutlicher nachzuzeichnen. Richard dagegen steckt schon lange, wenn auch unwillig, im System der Todesmaschinerie. Es ist nicht leicht dem Text zu entnehmen, ob Richard Mitglied einer Widerstandsbewegung ist. Es scheint, dass dies nicht der Fall ist, dass er eigentlich nur, obwohl er wie Franz gegen das NS-System ist, den Menschen, die er kennt, hilft, weil der Augenblick das vom ihm erfordert. Erst in einer bestimmten Situation wird er gewissermaßen - bis jetzt passiv - zur Handlung und damit zur Stellungnahme gezwungen. Es ist ähnlich wie in Schlagschatten, wo Richard eigentlich nur oberflächlich und ohne jegliche Überzeugung als Heimwehrmann die Interessen seiner Gesellschaftsschicht vertritt. In Totale Verdunkelung sagt Franz uiber die Haltung Richards: „Der trug schon damals das Kleid der anderen und handelte trotzdem nicht wie sie.“ (TV, S. 132) Mit "damals“ meint er das Jahr 1934. Nachdem Franz Richard im Fall der Inge Grazl geholfen hat, entscheidet sich Franz, bei Richard Hilfe für Gretl Dvořak-Liebeneder zu suchen. Er beginnt ihm endlich zu vertrauen und spürt, dass sein Vorgesetzter zu seiner Welt gehört. 
Sowohl Franz Prannowitz als auch Richard Wohlleben widersetzen sich dem herrschenden Regime erst dann aktiv, wenn eine konkrete Situation sie dazu zwingt, da den Personen aus ihrer nächsten Umgebung Unrecht geschehen ist. Beide kommen zum Schluss, dass sie in diesem Bereich zuwenig getan und sich dadurch schuldig gemacht haben. „[...] Wir alle, wir sind im Grunde doch mitschuldig. Weil wir Unrecht geduldet haben“ (TV, S. 157), stellt Franz im Gespräch mit Herbert fest. ${ }^{356}$ „Ich weiß und ich weiß jetzt, nun erst, daß es zuwenig ist, immer zuwenig gewesen ist" (TV, S. 181), sagt Richard im Gespräch mit seinem Vorgesetzten Oberstleutnant Perkal, worauf er ihn tröstet: „Zuwenig, Wohlleben, das wird es immer sein. Wohlleben. Wir werden immer zuwenig für die gerechte Sache tun. Was wir auch machen, das Soll werden wir nicht erreichen" (Ebd.). Dieses Gespräch, neben dem mit der alten Jüdin, bildet den Höhepunkt in Richards Entwicklung. Unter dem Schock, den die Informationen über die Massenvernichtung an Juden hervorgerufen haben, wird Richard sich der Unzulänglichkeit seiner Handlungen bewusst: „Ich habe mir bis heute eingebildet, es genügt das, was wir machen, mehr können wir nicht von uns verlangen, und man dürfe nicht mit denselben Mitteln arbeiten, die jene anwenden, gegen die man ist. Aber heute [...]" (Ebd.)

Neben den Hauptfiguren Richard Wohlleben und Franz Prannowitz gibt es noch Nebenfiguren, die - wie die Hauptfiguren - aus verschiedenen Lagern stammen und am Widerstand im herkömmlichen Sinne des Wortes, der mehr als individuelle Widerstandshandlungen wie kritische Äußerungen oder das Abhören ausländischer Sender umfasst, beteiligt sind. Eine dieser Personen ist der Sozialist Groß, den Prannowitz während seines Aufenthaltes in Wien zufällig trifft und

${ }^{356}$ Beide tragen nach Karl Jaspers moralische Schuld, die dann eintritt, wenn eigene Taten mit dem eigenen Gewissen kollidieren (Gebärden wie der Hitlergruß, Teilnahme an Versammlungen oder Ähnliches) und metaphysische Schuld, die den Mangel an absoluter Solidarität von Menschen untereinander betrifft. Jaspers unterschied zwischen krimineller, politischer, moralischer und metaphysischer Schuld und lieferte damit auf der individuellen und kollektiven Ebene eine konkrete Hilfe für den Umgang mit der Vergangenheit. Jaspers, Karl: Die Schuldfrage. Zur politischen Haftung Deutschlands. München 1946. Zitiert nach: Wielenga, Friso: Schatten deutscher Geschichte. Der Umgang mit dem Nationalsozialismus und der DDR-Vergangenheit in der Bundesrepublik. Aus dem Niederländischen v. Christoph Strupp. Vierow b. Greifswald: SH-Verlag 1995 (=Kölner Beiträge zur Nationsforschung, Bd. 3), S. 33f. 
der ihm von der Tätigkeit der Widerstandskämpfer im zehnten Bezirk berichtet. Auf Grund von Franzens politischer Zugehörigkeit kann man annehmen, dass dieser Widerstand hauptsächlich von Sozialisten getragen wird. Er besteht vor allem aus der Herstellung von Flugblättern, die zur Sabotage und Niederlegung der Arbeit aufrufen und der Hilfe für die Familien der hingerichteten Widerstandskämpfer.

Die andere Seite des Widerstands wird am Beispiel des Vorgesetzten Wohllebens, des Oberstleutnants Perkal, gezeigt. Er war es, der Wohlleben mit der Rettungsaktion für Inge Grazl beauftragt hat. Er hat auch die Wahrheit über die Massenvernichtung in den Konzentrationslagern gekannt und die Befürchtungen Richards bestätigt, der nach dem Treffen mit der jüdischen Malerin noch gehofft hat, dass es sich um Geruichte handelte. Perkal scheint die Malerin auch zu kennen, denn er besitzt eines ihrer Bilder. Wahrscheinlich war er auch am Attentat auf Hitler am 20. Juli 1944 beteiligt, jedenfalls hat er manche der Verschwörer gekannt. Im Roman werden Hauptmann Ettenreich und Unteroffizier Rainer genannt. Es sind erfundene Namen, wie Alois Vogel erklärt, die darauf hindeuten, dass es ähnliche Personen im Wehrkreiskommando XVII gegeben habe und dass es sich hier um die Gruppierung um den Major Szokoll gehandelt haben könnte. ${ }^{357}$ Major Szokoll war einer der Verschwörer vom 20. Juli 1944, der im Gegensatz zu Oberst Robert Bernardis und Rudolf Graf Marogna-Redtwitz nach dem Scheitern des „Unternehmens Walküre“ nicht entdeckt wurde. ${ }^{358}$ Oberstleutnant Perkal, der in Totale Verdunkelung für Major Szokoll stehen könnte, hatte Verbindungen zum englischen Geheimdienst, der gleich am folgenden Tag detailliert über die Sprengung eines deutschen Zuges mit fünfzig mit Benzin beladenen Waggons in der Ebene von Udine und Vicenza informiert hat. Man kann also annehmen, dass Oberstleutnant Perkal mit den Alliierten zusammengearbeitet hat. Nach dem Zwischenfall in seinem Haus in Döbling, bei dem Wohlleben einen jungen SS-Mann getötet hat, wird Perkal verhaftet. Nach einem kurzen Aufenthalt in der Untersuchungshaft kommt er mit gebrochenem Arm wieder zurück. Perkal hat auch Dr. Mayerhofer, den Leiter der Druckerei in Klosterneuburg, gekannt. Wohl selbst ahnungslos hat Wohlleben Franz Prannowitz dorthin geschickt, da er ihn etwas dazuverdienen lassen woll-

${ }^{357}$ Antworten Alois Vogels auf die Fragen der Verfasserin v. 28.8.2001.

${ }^{358}$ Kleindel: Österreich, S. 374. Als Leiter des militärischen Widerstandes nahm Major Szokoll mit dem sowjetischen Oberkommando Verhandlungen über die Abkürzung der Kämpfe um Wien auf. 
te. Beim Verhör durch die SS scheint es, dass Richard wirklich keine Ahnung gehabt hatte, welche Art von Texten in Klosterneuburg gedruckt wurden. Ob Perkal davon gewusst hatte, bleibt ungewiss. Sicher ist dagegen, dass Franz die in Klosterneuburg gedruckten Flugblätter an den Genossen Groß weitergegeben hatte. Man hat den Eindruck, dass Dr. Mayerhofer eine Vermittlungsinstanz zwischen dem Lager der ehemaligen Vertreter des Ständestaates, das durch den Oberstleutnant Perkal und den Oberleutnant Richard Wohlleben repräsentiert wird und dem Lager der Sozialisten, das durch den Genossen Groß und den Luftwaffenflieger Franz Prannowitz vertreten wird, darstellt. Die enge Zusammenarbeit der beiden Gruppen wird mit Ausnahme der zwei konkreten Fälle, Franz und Richard - nicht gezeigt.

Dies entspricht der Feststellung Wolfgang Neugebauers, dass es Kontakte und gegenseitigen Respekt zwischen dem Lager der Sozialdemokraten, Kommunisten, Gewerkschaftern und anderen Linksgruppen auf der einen Seite und dem der ehemaligen Christlichsozialen, Heimwehrangehörigen, Monarchisten und Katholiken auf der anderen Seite gegeben hat. Obwohl im Widerstand die Grenzen zwischen den beiden Gruppen verwischt wurden, gab es in der Regel keinen gemeinsamen, sondern einen rechten und einen linken Widerstand. . $^{359}$

Allerdings kommt im Roman der kommunistische Widerstand, der den weitaus stärksten unter allen politischen Gruppen $^{360}$ darstellte, nicht deutlich zum Ausdruck. Man kann nur annehmen, dass Sozialisten wie Groß auch mit Kommunisten zusammengearbeitet haben, denn er erwähnt einmal auch Kommunisten, mit denen er Kontakte pflegte.

In seiner sozialen Struktur war der österreichische Widerstand ein Widerstand der Arbeiter und der Intelligenz, ${ }^{361}$ die bei Vogel jeweils von Franz Prannowitz und Groß, sowie von Richard Wohlleben und Oberstleutnant Perkal vertreten werden. Am Widerstand nahmen auch vermehrt Personen teil, die bereits durch die Hölle der KZs gegangen waren und daher genau wussten, wofür sie kämpften. Sie arbeiteten am Wiederaufbau des Widerstands nach der weitgehenden Zerstörung

\footnotetext{
${ }^{359}$ Neugebauer: Widerstand und Opposition, S. $538 \mathrm{f}$.

${ }^{360}$ Ebd., S. 541, s. auch Botz: Nationalsozialismus in Wien, S. 352.

${ }^{361}$ Hanisch: Der lange Schatten des Staates, S. 392.
} 
der österreichischen Widerstandsgruppen $1939 / 40 .^{362}$ Diesen Gestalttypus stellt in Totale Verdunkelung Dr. Mayerhofer dar.

Zusammenfassend kann festgehalten werden, dass in Totale Verdunkelung viele Arten des Widerstands in verschiedener Intensität präsentiert wurden. Der organisierte Widerstand, den Hanisch dem Dreierschema von Botz folgend ${ }^{363}$ einen politischen nennt, bildet hier eher eine Randerscheinung und wird vor allem von Nebengestalten wie Groß und Perkal vertreten. Der Bogen des nichtorganisierten Widerstandes reicht im Roman von antinazistischer Haltung und den so genannten ,heimtiickischen Äußerungen' über das verbotene Abhören ausländischer Sender bis hin zur Hilfeleistung für Verfolgte (Inge Grazl und Gretl Dvořak-Liebeneder). Die Wurzeln dieses Widerstands, der keineswegs geringer als der organisierte Widerstand war und ebenso wie jener verfolgt wurde, waren, wie Neugebauer schreibt, ,humanitäre Erwägungen, Mitleid für den verfolgten Nächsten, Abneigung und $\mathrm{Ha} \beta$ gegen ein verbrecherisches Regime. ${ }^{\text {“364 }}$ Dies waren auch die Beweggründe für das Handeln von Alois Vogels. Helden. Es ist für die Art der Figurenzeichnung in den Romanen von Alois Vogel bezeichnend, dass ausgerechnet der individuelle Widerstand im Mittelpunkt steht, denn es war die Intention des Autors, die Geschehnisse jener Zeit aus der Perspektive eines Durchschnittsmenschen darzustellen: „Ich sah meine Arbeiten, im besonderen natürlich die beiden Romane [...] auch als Zeugnis eines der dieses Geschehen miterlebt hat, als Zeugnis aus der Perspektive ,von unten', soll heißen, von dem Blickwinkel des einfachen Menschen, nicht jenes des Staatsmannes oder Herrschers, aber auch nicht von dem des Geschichtsdozenten." ${ }^{365}$

Ein gutes Beispiel für das aufkeimende Österreichbewusstsein der Sozialdemokraten, von denen viele noch vor dem Krieg großdeutsch eingestellt waren, ist die tiefe Überzeugung Franzens, die er im Gespräch mit Herbert zum Ausdruck bringt, dass Österreich nach dem Krieg frei und unabhängig sein werde. Auf den Einwand seines

${ }^{362}$ Dusek, Pelinka, Weinzierl: Zeitgeschichte im Aufriß, S. 247.

${ }^{363}$ Zwei weitere Stufen waren: sozialer Protest und abweichendes Verhalten. Vgl. Gerhard, Botz: Methoden- und Theorieprobleme der historischen Widerstandsforschung. Arbeiterbewegung, Faschismus, Nationalbewußtsein, hrsg. v. Helmut Konrad u.a. Wien: 1983, S. 137-152, zitiert nach Hanisch: Der lange Schatten des Staates, S. 390.

${ }^{364}$ Neugebauer: Widerstand und Opposition, S. 548.

${ }^{365}$ Brief A lois Vogels v. 17.11.1999. 
zweifelnden Gesprächspartners, der die These vertritt, dass der österreichische Staat nach dem Ersten Weltkrieg nicht lebensfähig war, liefert Franz folgende Erklärung: „Weil jeder gegen jeden war. Weil wir nicht zusammengearbeitet haben. Weil die Schwarzen die Demokratie umgebracht und die Sozialdemokraten von der Diktatur des Proletariats gesprochen haben." (TV, S. 152) Die beiden Gesprächspartner greifen auch die umstrittene These von Österreich als erstem Opfer des Nationalsozialismus auf. Franz ist der Ansicht, die von vielen nach dem Krieg vertreten wurde, dass Österreich das erste Opfer des Faschismus gewesen sei, worauf Herbert ihn spöttisch an die jubelnden, Hitler begrußenden Massen am 15. März 1938 erinnert. (TV, S. 151) Franz wendet ein, dass am selben Tag einige Tausend Österreicher verhaftet und nach Dachau gebracht wurden, was sein Gegeniiber relativiert und Franz zu erklären versucht, dass er selbst als Sozialdemokrat keinen Schaden im NS-Staat erlitten habe, sondern sogar mit dem Eisernen Kreuz ausgezeichnet wurde.

Die Zusammenarbeit Franzens mit Richard in der Feuerwehrzentrale in den letzten Kriegstagen kann als eine solide Grundlage für einen neuen, unabhängigen österreichischen Staat gedeutet werden. Die ehemaligen Gegner sind endlich die alten Vorurteile losgeworden und wollen die Kriegsvergangenheit vergessen, sind sich dabei aber ihrer Schuld bewusst. Sie arbeiten zusammen für die Zukunft. Der unerwartete Entschluss Franzens, bei der Feuerwehr ,unterzutauchen“, lässt sich unterschiedlich interpretieren. Einerseits wollte er vielleicht nicht mehr auf der Seite des Dritten Reiches stehen, da er von dieser Idee nie überzeugt gewesen war. Andererseits kann die Tatsache, dass er sich erst so spät entschließt, zu der Annahme führen, er habe Repressalien seitens der anrückenden russischen Armee befürchtet, falls diese ihn in der Uniform der Wehrmacht antreffen sollten.

\section{Kollaboration}

Obwohl die Aufmerksamkeit des Lesers auf die Gestalten, die sich dem herrschenden Regime widersetzten, gelenkt wird, wird im Roman sichtbar, dass der Großteil der Bevölkerung aus verschiedenen Gründen die Diktatur akzeptiert oder zumindest duldet. Dies kommt in ihrem Verhalten oder ihren Aussagen zum Ausdruck. Entweder sind es Menschen wie Steffi und Herbert, die schon viel erleiden mussten und einfach aus Angst nun eine Art „Vogel-Strauß-Politik“ 
betreiben, und annehmen, dass sie sowieso nicht imstande seien, etwas zu ändern. "Diese verdammte Politik [...] Genug, dass sie Herbert das Bein gekostet hat. Wir wollen nichts mehr davon wissen, gelt? [...] Darum ist es gescheiter, man lebt still in seinen vier Wänden und kümmert sich nicht um das, was die Großen machen." (TV, S. 154f.) Oder es sind Menschen wie Poldi Mihatsch und ihre Mutter, die das System von ganzem Herzen bejahen, obwohl auch deren Beziehung zum NS-Staat, besonders in seiner letzten Phase, durch Angst gekennzeichnet ist. „Am besten ist jetzt überhaupt: nicht auffallen, überhaupt nicht vorhanden sein. Man weiß ja von einem Tag auf den anderen nicht, was noch kommt" (TV, S. 147), sagt Frau Mihatsch, die sich rümt, eine gute Deutsche zu sein. Ein anderes Beispiel ist, wie schon früher erwähnt, Helmut Brünner.

Viele Menschen, die vor 1938 einer anderen politischen Gruppierung angehört haben, wurden Nationalsozialisten. Viele ehemalige Kollegen von Franz Prannowitz haben diesen Sinneswandel vollzogen. Bei seinem ersten Fronturlaub ist Franz über die Allgegenwart des Hitlergrußes schockiert: „[...] der Schmidt sagte Heil Hitler, als ich ihn ansprach, jeder sagte Heil Hitler, als man ihn ansprach." (TV, S. 141) In diesem Roman wird besonders der Übergang der Sozialisten zu den Nationalsozialisten geschildert. Das konstatiert Franz als er seinem Bekannten Groß im zehnten Bezirk begegnet und die ihm einst bekannte Gegend von der Straßenbahn aus beobachtet. Er erinnert sich dabei daran, wie schnell dieser Wandel in den Tagen vor der „Volksabstimmung“ am 10. April 1938 vor sich ging:

Ein Parteilokal hatten sie aus dem Arbeiterheim gemacht. Die Fahne hing Tag und Nacht hier, eine rote Zunge, auf die man eine wieBe Pille gelegt hatte, eine bittere Pille. Die Fahne! Zuerst an dem Kandelaber auf der Opernkreuzung, dann vor dem Bundeskanzleramt und schließlich auf der Hofburg. Die Fahnen, auf die ihn Dožekal am 10. April aufmerksam machte, als sie nach der Abstimmung durch die beflaggten Straßen gingen. „Da, da, da, das waren doch noch im Jahre 34 alles Genossen!" Überall lag die weiße Pille auf dem roten Tuch. Auf Rot in goldenen Buchstaben, mit papierenem Eichenkranz umwunden, standen und hingen in den Fenstern der Proletarier und Kleinbürger die ovalen Schrifttafeln: EIN VOLK! EIN REICH! EIN FÜHRER! oder DEIN JA DEM FÜHRER! (TV, S. 90)

Es ist charakteristisch für Franz Prannowitz, dass er sehr aufmerksam ist und ein gutes Wahrnehmungsvermögen besitzt, daher findet 
er iberall und in fast jeder Situation etwas Lustiges oder Komisches. Eines Tages, als er von der Arbeit, die er nach vielen Jahren Arbeitslosigkeit endlich bekommen hat, nach Hause geht, bemerkt er die Hakenkreuzfähnchen an einem ziemlich ungewöhnlichen, unpassenden Ort. Er ging ,an den Auslagen des Schustermeisters vorbei; in denen steckten in zwei schwarzglänzenden Galoschen zwei Hakenkreuzwimpel und zwar so, dass sich die Stäbchen, an die das rote $\mathrm{Pa}$ pier geklebt war, über frischbesohlten Damenstöckelschuhen kreuzten" (Ebd.). Gleichzeitig erinnert sich Prannowitz auch an die Wandzeitung der Deutschen Arbeitsfront aus demselben Jahr:

[...] die großen KdF-Schiffe, die das Zahnrad in der Flagge führten und an deren Reling fröhlich winkende Menschen standen; die rings von Wäldern umgebenen Erholungsheime, die Siedlungen, Häuschen neben Häuschen, jedem Arbeiter sein Eigenheim, dazwischen spielende Kinder, junge, saubere Frauen mit blondem, strähnigem Haar, ihren Kleinsten auf dem Arm, glänzende Wangen, nirgends Schmutz, überall Lächeln, Schönheit, Wohlgestalt; daneben zwei Bilder: ein verdreckter Fabrikshof und darunter, was die Aktion KRAFT DURCH FREUDE aus ihm gemacht hat, einen Garten mit dichtem Rasen, Blumenbeeten und Ziersträuchern. Bilder in grünlichem Druck auf leicht glänzendem Papier, und über allem das Spruchband DEIN DANK DEM FÜHRER! (TV, S. 91)

Damals versuchte Prannowitz vor dem über diese Heuchelei empörten Dožekal die nationalsozialistische Sozialpolitik zu verteidigen, indem er sagte, dass sie immerhin Leistungen für die Arbeiter aufzuweisen habe. Auf die Bemerkung seines Gesprächspartners, dass dahinter ausschließlich Aufrüstung stecke, erwiderte er, dass jeder leben wolle und nicht danach frage, warum er - jahrelang arbeitslos - in ein neues Haus einziehen dürfe und endlich den Unterhalt für seine Familie verdienen könne.

Diese von Vogel angedeutete besondere Anfälligkeit der Sozialdemokraten gegenüber dem Nationalsozialismus stimmt mit dem von Gerhard Botz beschriebenen Prozess der Gewinnung der Arbeiterschaft überein. Die vom Nationalsozialismus kultivierte Arbeiterideologie, die eigentlich eine Arbeitsideologie war und Ersatzfunktion für praktische Arbeiterpolitik erfüllte, sprach „breite Randschichten der Arbeiterschaft, vor allem die Angestellten und Arbeitslosen, in beträchtlichem Ausmaß an. ${ }^{\text {"366 }}$ Ihr Ziel war, die Arbeiterschaft nicht

${ }^{366}$ Botz: Nationalsozialismus in Wien, S. 129. 
einzuschüchtern, sondern sie durch Aktionen der „Deutschen Arbeitsfront“ und ihrer Trägerin „Kraft durch Freude,“ das „Winterhilfswerk des deutschen Volkes," durch kostenlose Urlaubsangebote für Arbeiter und Kinder im Reich sowie durch die „Armenausspeisung" der deutschen Wehrmacht, für sich zu gewinnen. Solche Maßnahmen begannen bereits in der Zeit vor der "Volksabstimmung" am 10. April 1938 und wurden danach fortgesetzt. Besonderes Gewicht legten die neuen Machthaber auf die Gewinnung der Arbeitslosen, deren Zahl im Jänner 1938 noch 401.000 betrug. ${ }^{367}$ Dies sollte durch die Wiedereingliederung in den Arbeitsprozess geschehen. Viele von den Eingestellten waren 1934 aus dem Dienst entlassene Sozialdemokraten und Kommunisten. Nur wenige unter ihnen lehnten diese Angebote aus politischen Gründen ab, viele stimmten dem neuen Regime nach außen hin zwar zu, blieben jedoch ihrer früheren Weltanschauung treu. Das Überlaufen vieler Menschen mit „marxistischer" Vergangenheit erklärt Botz damit, dass sie in einem viel gröBeren Ausmaß der Arbeitslosigkeit ausgesetzt waren als Christlichsoziale oder „Vaterländische,“ die durch ihre frühere Position geringere Möglichkeiten hatten, jetzt einen günstigen Posten im öffentlichen Dienst zu erhalten. Ihr Gesinnungswandel wäre weniger glaubhaft gewesen wie der der Sozialdemokraten oder Kommunisten. Außerdem verband die Sozialdemokraten mit den Nazis sozusagen eine gemeinsame Erfahrung der Gegnerschaft und Haft im Ständestaat. ${ }^{368}$ Diese Prozesse werden im Roman veranschaulicht durch die Wandzeitung der Deutschen Arbeitsfront, Franzens Beobachtungen seiner Umgebung, seine Erklärung für das Verhalten mancher Menschen gegenüber den Erfolgen der NS-,,Sozialpolitik" und die Tatsache, dass er selbst - jahrelang arbeitslos - Arbeit gefunden hat. Auch ein kurzer Gedanke Wohllebens, der Franzens Einstellung zum NS-Regime in Erfahrung zu bringen versucht, sagt viel über die Situation der ehemaligen Sozialdemokraten aus. , [...] wie viele kommen auch von dort, von wo du herkommst und zeigen heute ihre ehemaligen Kameraden an." (TV, S. 82) Hier ist natürlich schon vom Jahr 1944 die Rede.

Gerhard Botz weist auch auf die Rolle des „Völkischen Beobachters" in dem Werben um die österreichische Arbeiterschaft hin, ${ }^{369}$ was bei Vogel ebenfalls erwähnt wird. „Auch die sozialistischen

${ }^{367}$ Ebd., S. 134.

${ }^{368}$ Ebd., S. 136.

${ }^{369}$ Ebd., S. 133. 
Funktionäre stimmten für Großdeutschland, im ,Völkischen Beobachter" war es gestanden" (TV, S. 81). Ein Foto vom Goethehof, der im Februarkrieg des Jahres 1934 eines der Zentren des sozialdemokratischen Widerstands war, wird vor der „Volksabstimmung“ mit Werbeparolen umgeben wie: „Friede, Arbeit, Brot - wir alle helfen dem Führer" oder „Nicht Klassenkampf, sondern Werte schaffen!‘370 veranschaulicht diesen raschen Sinneswandel vieler Sozialdemokraten.

\section{Zusammenfassung}

Die Absicht des Autors war es, ein möglichst differenziertes Bild der Gesellschaft in den Zeiten des Zweiten Weltkrieges zu entwerfen und neben der Kollaboration oder wenigstens der Zustimmung der österreichischen Bevölkerung, auch den Widerstand oder zumindest den Mangel an Akzeptanz gegenuiber dem Regime des Dritten Reichs aufzuzeigen. Mit einer bloßen Gegenüberstellung von Zahlen - 700.000 NSDAP-Mitglieder gegenüber 100.000 Widerstandskämpfer ${ }^{371}$ in Österreich - kann man es nicht abtun. Das Vorhaben des Romanciers ist es auch, die Mechanismen zu präsentieren, die zu dieser schweigenden Akzeptanz geführt haben.

„Totale Verdunkelung“ [...] löste vor allem dann jene Welle der Veröffentlichungen der jungen österreichischen Schriftsteller aus, die damals noch lange nicht lebten, die aber so schrieben als wären alle Österreicher blindlings den Nazis verfallen gewesen. Sicher waren es sehr viele, doch wer die Zeit nicht erlebt hat, weiß auch nicht, daß jeder der damals ein unbedachtes Wort in der Öffentlichkeit gegen das Regime sprach, sehr gefährdet war. Darum schwiegen die meisten, die mit dem Regime nicht einverstanden waren. Immerhin hat es tausende Verhaftungen und Verschickungen ins (sic!) KZs gegeben und sehr viele von den Nazis Ermordete. All dieser Opfer wurden (sic!) von den Jungen nicht nur nicht gedacht, sondern mit ihrem Pauschalurteil bagatellisierten sie auch deren Widerstand. ${ }^{372}$

Dabei wählt der Romancier für seine Darstellung - im Gegensatz zu manchen jüngeren Autoren, denen es auf Grund ihres Alters nicht möglich war und die er für ihre Pauschalurteile der ganzen Genera-

\footnotetext{
${ }^{370}$ Ebd., S. 146.

${ }^{371}$ Neugebauer: Widerstand und Opposition, S. 549.

${ }^{372} \mathrm{Brief} A$ lois Vogels v. 4.8.2001.
} 
tion gegenüber kritisiert - die Position eines Augenzeugen. Wie er immer wieder betont, möchte er mit seinen Romanen ein Zeugnis ablegen, wozu er sich verpflichtet glaubt:

Warum nun [...] diese Thematik? Warum der Griff in diese Zeit 1934, 1938, 1945? Weil wir zur Zeugenschaft verpflichtet sind und weil alles jederzeit wiederholbar ist. Weil da und dort die Zeichen darauf hinweisen, daß ähnliche Situationen reifen und daß andere Generationen vor ähnliche Probleme gestellt werden. Zeugenschaft, in der Hoffnung, daß die Zeichen an der Wand erkannt werden. Wissend, daß jede Generation ihren Weg gehen muß, daß die Jungen nur das glauben, was sie selbst erlitten haben. Und doch immer wieder Zeugenschaft! ${ }^{373}$

\subsubsection{Die Unstimmigkeit der historischen Fakten}

Im vorigen Abschnitt wurde die Aufmerksamkeit auf die Stimmigkeit der in Totale Verdunkelung dargesteliten Welt mit historischen Tatsachen und Entwicklungen gelenkt. Totale Verdunkelung ist im Vergleich mit Schlagschatten in einem höheren Ausmaß zeitgeschichtlich verankert. Am Beispiel von Schlagschatten sollen neben Stimmigkeiten auch manche Unstimmigkeiten oder Abweichungen von der so genannten historischen Wahrheit aufgezeigt werden. Ein Beispiel für Stimmigkeit in Schlagschatten ist das Schicksal Hans Brïnners, der nach seiner Flucht aus der Tschechoslowakei von Gendarmen festgenommen und ins Gefängnis gebracht wurde, weil sie ihn für einen Schmuggler hielten. Bei der Flucht kamen ihm illegale Nazis zu Hilfe, die annahmen, er sei einer von ihnen. Dieses Ereignis erinnert an den von Gerhard Jagschitz beschriebenen Fall Bernaschek. ${ }^{374}$ Allerdings beteuert Alois Vogel, dieses Buch nicht gekannt zu haben, denn zur Zeit als er an seinem Roman gearbeitet hat, war Jagschitz' Buch noch nicht veröffentlicht. Man könnte es ein Paradoxon nennen, das beweist, wie eng die in den Romanen Alois Vogels dargestellten Figuren und Geschehnisse mit der historischen Wahrheit verbunden sind. Ebenso wahrscheinlich kann es aber sein, dass der Autor, der sich vieler unterschiedlicher Quellen bedient hat, aus der Zeitungslektüre davon erfahren hat und diese Figur und Situation somit der Realität entnommen wurden. Es kann aber auf Grund der

${ }^{373}$ Vogel: Von Durchbruch zu Durchbruch, S. 6.

${ }^{374}$ Jagschitz: Der Putsch, S. 39. 
Fülle an Quelleninformationen wohl nicht mehr jedes Detail auf seine Herkunft zurückverfolgt werden.

Es sollen aber auch einige Beispiele für Textstellen, die Unstimmigkeiten aufweisen, angeführt werden. Richard Wohlleben sieht kurz vor dem Angriff der nationalsozialistischen Putschisten auf das Haus der RAVAG etwa zehn Männer in der Uniform des Bundesheeres. Nach der Darstellung Gerhard Jagschitz' waren jedoch nur die Putschisten im Bundeskanzleramt mit den Uniformen des Bundesheeres bekleidet, die in der RAVAG trugen Zivil. ${ }^{375}$ In der Beschreibung Jagschitz' wird Erich Schredt genannt, einer der Putschisten, der zusammen mit Wilhelm Waneck (beide Mitglieder der SS-Standarte 89) für die militärische Leitung verantwortlich war. ${ }^{376}$ Die Vermutung, dass Alois Vogel bei der Gestaltung der Figur Erich Wohllebens die Gestalt Erich Schredts gemeint haben könnte, wurde von ihm allerdings verneint. ${ }^{377}$ Der in Schlagschatten genannte Schneeberger, der ein naher Mitarbeiter Röhms gewesen sein soll, konnte nicht identifiziert werden. Der Nationalsozialist, der Hans Brünner bei der Flucht hilft, brachte den „Verräter Schneeberger,“ wie er ihn nennt, um. (Schl., S. 256) Dazu äußerte Alois Vogel, dass sowohl die Namen Erich Schredt und Schneeberger (Schlagschatten) als auch Oberstleutnant Perkal (Totale Verdunkelung) und selbst Richard und Erich Wohlleben komplett erfundene Namen seien. Wie bereits erwähnt, hat Vogel bemerkt, dass er den geschichtlichen Hintergrund für seine Romane unter anderem durch Lektüre der Zeitungen verschiedener politischer Richtungen genau recherchiert hat. ${ }^{378}$ Dabei standen ihm manche Personen, die er befragt oder gekannt hat, Modell, was aber nicht gleich bedeutet, dass seine Romangestalten genaue Abbildungen dieser Modelle waren: „ [...] auch die Personen, die mir Modell standen, handelten nicht so wie in dem Roman, sondern waren mir nur Modell. Und wenn sich die Handlungen der Romanfiguren mit gewissen historischen Figuren / Personen (z. T.) decken, so i s t [Hervorhebung des Autors] es Zufall." ${ }^{379}$ Wie man sieht, hat der Romancier ein ziemlich lockeres Verhältnis zu den Quellen, er schöpft daraus das, was ihm brauchbar zu sein scheint. Im Allgemeinen ist er aber

\footnotetext{
${ }^{375}$ Ebd., S. 113.

${ }^{376} \mathrm{Ebd}$.

${ }^{377}$ Brief Alois Vogels v. 3.7.2000.

${ }^{378}$ Ebd., s. auch Antworten Alois Vogels auf die Fragen zum Referat im Dissertantenkolloquium am 9.6.1998.

${ }^{379}$ Brief Alois Vogels v. 3.7.2000.
} 
um die Plausibilität seiner Romane bemüht, denn er behält den Grundton und die Atmosphäre der Zeit bei. Die Freiheit, die er sich nimmt, beschränkt sich auf die fiktiven Gestalten, die jedoch teil weise ihre Entsprechungen in der Wirklichkeit haben, denn die meisten Figuren in seinen Romanen haben reale Personen als Modell. Diese Modelle waren keine großen, allgemein bekannten historischen Persönlichkeiten, sondern vielmehr so genannte „durchschnittliche" Menschen. Diese Methode erlaubt dem Autor, Schicksale seiner Figuren frei zu gestalten und gleichzeitig den historischen Hintergrund möglichst wirklichkeitsgetreu darzustellen. Man könnte mit der Feststellung Alois Vogels zusammenfassen: „Die Aktionen der handelnden Personen sind Fiktionen in der Faktizität der historischen Situationen $[\ldots]^{4 / 380}$

\subsection{Wozu dient Geschichte in den Romanen Alois Vogels?}

Geschichte spielt bei vielen Autoren erzähltechnisch eine äußerst bedeutende Rolle. Die komplizierten, historischen Ereignisse, die sich in den Romanen Alois Vogels in einer düsteren Zeit abspielen, sind als Hintergrund und gleichzeitig als Kontrast im Sinne der Hervorhebung und Glorifizierung der Taten von Menschen konzipiert, die in den Romanen eine positive Rolle spielen. Sie zeigen, dass man unabhängig von der sie umgebenden Wirklichkeit - seine Menschlichkeit bewahren kann. Die Geschichte zwischen Leni und Richard Wohlleben hätte wahrscheinlich andere Formen angenommen, wenn sie sich zu Friedenszeiten abgespielt hätte, wenn ihre Beziehung nicht im Schatten der vor kurzem stattgefundenen Februarkämpfe gestanden wäre, die die zwischen ihnen bereits bestehende Kluft noch vertieft haben. Die Umstände, unter denen die Protagonisten aufeinander treffen, tragen dazu bei, dass der spontane Entschluss Richards, einem Kind zu helfen, ohne anfangs zu wissen, dass es der Sohn eines Schutzbündlers ist, noch dramatischer erscheint. „Die unselige Politik bildet nur den kontrapunktischen Rahmen einer Glorifizierung des

${ }^{380}$ Antworten Alois Vogels auf die Fragen zum Referat im Dissertantenkolloquium am 9.6.1998. 
Menschen, die gerade durch ihre schlichte Andeutung ergreift, “381 schreibt Albert Janetschek. „Der Mensch und seine persönliche Entscheidung oder Nichtentscheidung, seine Eingebundenheit und sein offenbares Ausscheren aus seinen uberkommenen Voraussetzungen war mir wichtig aufzuzeigen, “382 bestätigt der Romancier.

Es lohnt sich bei dieser Gelegenheit am Rande zu erwähnen, dass in Bezug auf das Gesamtwerk Alois Vogels fast als Regel betrachtet werden kann, dass sich seine Protagonisten besonders in einer schweren Zeit als Menschen bewähren, während die Helden in der weniger traumatischen Periode der fünziger Jahre, in der die Romane Jahr und Tag Pohanka oder Das blaue Haus spielen, oft menschlich scheitern. $^{383}$

In den zwei besprochenen Romanen ist also die Geschichte und die unmittelbare Zeitgeschichte kein Selbstzweck.

Obwohl Alois Vogel es nicht explizit ausdrückt, möchte er mit seinen Romanen auch belehren oder zumindest zum Nachdenken anregen. Er ist sich bewusst, dass die Menschen aus der Geschichte oft nichts lernen und die Lektüre seiner Romane sie nicht vor ähnlichen Fehlern bewahren kann, getreu dem dictum Hegels, „was die Erfahrung [...] und die Geschichte lehren, ist dies, daß Völker und Regierungen niemals aus der Geschichte gelernt und nach Lehren, die aus denselben zu ziehen gewesen wären, gehandelt haben." 384 Trotzdem

${ }^{381}$ Dst., AV-Mappe, Janetschek, Albert: Neue Bücher von „Podium"Autoren. In: Wiener Neustadt Nachrichten v. 4.11.1977, S. 16.

${ }^{382}$ Brief Alois Vogels v. 3.7.2000.

${ }^{383} \mathrm{Vgl}$. z.B. Attila Horvath in Das blaue Haus, ein Flüchtling aus Ungarn, dem in der Revolutionszeit seine Ideale am wichtigsten waren. Seinen Wohltäter, Herrn Pokorni findet er am Anfang abscheulich, weil sein ganzer Lebensinhalt sich auf das Essen und Trinken beschränkt, doch am Schluss wird er ihm immer ähnlicher. Oder Ingenieur Pohanka, der Titelheld des Romans Jahr und Tag Pohanka, der seiner eigenen Frau völlig überdrüssig geworden ist, und der nach einer Abwechslung bei seiner jungen Mitarbeiterin Kitty sucht, was dazu führt, dass seine Frau sich für seinen Kollegen zu interessieren beginnt. Beide Liebhaber verunglücken tödlich bei einem Autounfall und Pohanka bleibt mit drei Kindern allein.

${ }^{384} \mathrm{Vgl}$. Mann, Golo: Wie man aus der Geschichte nicht lernen soll. In: Geschichte und Geschichten. Frankfurt a.M.: S. Fischer 1961, S. 157-168. Zitat S. 168 sowie Koselleck, Reinhard: Historia Magistra Vitae. Über die Auflösung des Topos im Horizont neuzeitlich bewegter Geschichte. In: Natur und Geschichte. Karl Löwith zum 70. Geburtstag, hrsg. v. Hermann 
gibt er die Hoffnung nicht auf, dass ,die Zeichen an der Wand erkannt werden. ${ }^{\text {“385 }}$ Er vereinigt in seinen Romanen zwei auf den er'sten Blick ambivalente Einstellungen der Geschichte gegenüber: eine optimistische und eine pessimistische:

Pessimismus im begrenzten Sinn, nämlich, daß der Mensch immer erst durch das Leid und seine üblen Erfahrungen lernt und sich zu Besserem besinnt [...] Optimismus im weiteren, allgemeinen Sinn der menschlichen Entwicklung, nämlich, daß der Mensch alle Leiden, Krisen und Nöte überwindet und sich letztlich doch zu einem Punkt Omega hin entwickelt, einem Punkt Omega, der dem Alpha sehr nahe kommt. ${ }^{386}$

Seine Romane sind Veranschaulichungen dieser Aussage, besonders in Anbetracht der Schlüsse, ${ }^{387}$ wobei der Ausklang des ersten Romans die These, dass die Menschen aus der Geschichte nichts gelernt haben, bestätigen könnte, während das Ende des zweiten Romans in seiner Aussage viel positiver zu sein scheint. Die Verhaltensweisen der in den Romanen handelnden Hauptgestalten liefern einen Hinweis darauf, dass zumindest sie etwas aus der Geschichte gelernt haben, obwohl auch dies nicht ganz eindeutig ist. Davon zeugen könnte die Tatsache, dass Franz und Richard sich endlich, nach vielen Jahren, entschließen konnten zusammenzuarbeiten, was noch 1939 kaum möglich war und sogar am Kriegsende nicht ganz problemlos ablief. Es ist ihnen gelungen, alte Barrieren zu überwinden. Andererseits möchten sie aber einfach den bedürftigen Menschen helfen und benötigen dazu keine höheren Zwecke. Es würde wahrscheinlich zu weit gehen, diese Zusammenarbeit als Ergebnis des in der Moskauer Deklaration formulierten nötigen Beitrags Österreichs zu seiner Befreiung zu interpretieren. Der oft akzentuierte idealistische Glaube an die individuelle Entscheidungsfreiheit würde dagegen sprechen. Das macht den individuellen Widerstand gegen das herrschende Regime egal ob das der Austrofaschismus oder Nationalsozialismus ist - sinnvoll. ,[...] die Freiheit der Entscheidung nimmt uns niemand ab," sagt eine der Gestalten in Schlagschatten (Schl., S. 108).

Braun, Manfred Riedel. Stuttgart, Berlin, Köln, Mainz: W. Kohlhammer 1967, S. 196-219. Zitat S. 207.

${ }^{385}$ Alois Vogels Aussage über die Notwendigkeit, ein Zeugnis abzulegen.

Vgl. Vogel: Von Durchbruch zu Durchbruch, S. 6.

${ }^{386} \mathrm{Ebd}$.

${ }^{387}$ s. Romanschlüsse (5.6.6 Unterkapitel dieser Arbeit). 
Die wichtigsten Gestalten verwirklichen dieses Prinzip in ihrem Handeln, das aus menschlichen Regungen resultiert, die unabhängig von der Zeit sind, in der sie leben. Es ist, wie August Obermayer schreibt, ein bis zu einem gewissen Grad „klassischer Konflikt, dem sich die Charaktere Vogels ausgesetzt sehen, zwar nicht mehr auf der rigorosen Abstraktion von Pflicht und Neigung basierend, sondern viel mehr auf der dem psychologisierenden zwanzigsten Jahrhundert angemesseneren Dualität von prädestinativer Eingebundenheit und moralischer Selbstverwirklichung. ${ }^{* 388}$ Dass die Hauptfiguren früher oder später diese Eingebundenheit überwinden und sich als Menschen bewähren, spricht nicht dafür, dass die Geschichte einen direkten Einfluss auf sie hat oder dass sie etwas aus der Geschichte gelernt haben. Es kann hier lediglich von der indirekten Einwirkung die Rede sein, denn die historischen Ereignisse bringen sie nur dazu, dass diese Entscheidungen schneller in ihnen reifen - wahrscheinlich wären sie früher oder später zu denselben Schlüssen gekommen.

Dass Vogel sich zu einer Zeit, in der man sich weniger eingehend mit der Thematik der Zwischenkriegszeit und des Zweiten Weltkrieges beschäftigte, als ungefähr ein Dutzend Jahre später, trägt sicherlich dazu bei, dass sein Schaffen als eine Art der gegenwartspolitischen Auseinandersetzung angesehen werden kann. Er wollte die Aufmerksamkeit der Öffentlichkeit auf Themen lenken, die zu jener Zeit gemieden und tabuisiert wurden.

Joseph MacVeigh stellt in Bezug auf Schlagschatten fest, dass dieser Roman eine „Auseinandersetzung mit dem Faschismus in Österreich im historischen Gewand der austrofaschistischen Jahre ${ }^{6389}$ sei. Nicht der zweite Roman, wie man erwarten könnte, sondern bereits der erste der geplanten Serie wird von diesem Wissenschaftler als „Bewältigungsliteratur" angesehen. Die frühen dreißiger Jahre, als Hitler erst an die Macht gekommen war, sind für MacVeigh das Medium der Auseinandersetzung mit dem Phänomen, das erst einige Jahre später zu voller Geltung gekommen ist.

Wie in einem fruheren Kapitel dieser Arbeit bereits erwähnt wurde ${ }^{390}$ kann Geschichte auch als Mittel zur Distanzierung von der Sphäre des Persönlichen und Privaten dienen. Alois Vogel hat die Geschehnisse, die er in Schlagschatten darstellt, als zwölfjähriges Kind

\footnotetext{
${ }^{388}$ Obermayer: Nachwort zum 4. Band der 5-bändigen Werkausgabe, S. 483. ${ }^{389}$ MacVeigh: Kontinuitüt und Vergangenheitsbewältigung, S. 175

${ }^{390}$ s. Funktionen der Geschichte in der Literatur (2.2 Unterkapitel dieser Arbeit).
} 
selbst erlebt. Er hätte einen Ich-Roman schreiben können, hat sich jedoch für die Form eines personalen Romans entschieden, der ein scheinbar erzählerloser Roman ist, der durch das Vorherrschen szenischer Gestaltung, des Dialogs, der erlebten Rede und der Bewusstseinsspiegelung den Anschein objektiver Unmittelbarkeit erzeugt. ${ }^{391}$ Und eben diese Objektivität war Vogel sehr wichtig. ${ }^{392}$ Das Auftreten von biographischen Elementen in seinem Werk verneint der Autor vehement:

Es ist in meinem Werk nichts Biographisches [...], sondern nur etwas von mir Beobachtetes. Die Situationen, Menschen, die ich beobachtet habe sind drinnen, aber das bin nicht ich. Meine Erlebnisse, Ansichten, Gespräche sind es nicht, das sind Beobachtungen, die ich gemacht habe an den Herrn „A", „B" und „C". Die habe ich verfremdet, habe ich ihnen einen anderen Zusammenhang gestellt, wie ich sie gebraucht habe. Dieser Bub, der verletzt wird, das wäre vielleicht noch das Ähnlichste, das ich sein könnte. Das ist eine Nebenfigur, die altersmäßig auch mir entspricht. ${ }^{393}$

\subsection{Sind Schlagschatten und Totale Verdunkelung} historische Romane? - Versuch einer Gattungsbestimmung

Ein literarisches Werk einem bestimmten Genre zuzuschreiben, heißt, nach methodischen Vorentscheidungen eine von vielen möglichen Lesearten als dominant zu erklären. Man muss viele Merkmale berücksichtigen, um in der Heterogenität verschiedener Werke einen gemeinsamen Nenner zu finden.

Um entscheiden zu können, ob die in dieser Arbeit behandelten Romane als historisch gelten können, muss man von einer Definition dieses Genres ausgehen, wobei hervorgehoben werden muss, dass Geschichtsdichtung ein nicht einheitlich definierter Begriff ist. „Was darunter zu verstehen sei, bestimmen die jeweils zeitgebundenen Auffassungen von Dichtkunst und Wahrheit beziehungsweise Fiktionalität einerseits, die je spezifischen Anschauungsformen von Geschich-

${ }^{391}$ Stanzel: Typische Formen des Romans, S. 43.

${ }^{392} \mathrm{~S}$. Interview mit Alois Vogel im Anhang.

${ }^{393} \mathrm{Ebd}$. 
te andererseits. “394 Obwohl man sich der Unzulänglichkeit von vielen Definitionen bewusst ist, muss man von irgendeiner Definition ausgehen.

Eine von ihnen besagt, ein historischer Roman sei ,eine umfangreichere erzählende Dichtung, die beglaubigte geschichtliche Persön-

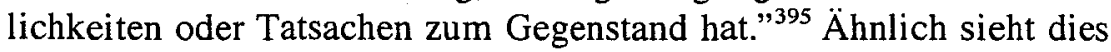
auch der Autor selbst, bloß, dass er als Bedingung die Behandlung von historischen Gegebenheiten angibt. „Ich würde die beiden Romane Schlagschatten und Totale Verdunkelung als historische Romane bezeichnen, vorausgesetzt, daß man historische Romane jene Romane bezeichnet, die sich mit historischen Gegebenheiten auseinandersetzen."396

Eine umfangreichere und detailliertere Begriffsbestimmung mit Berücksichtigung von historischen Ereignissen und Persönlichkeiten bietet Gero von Wilpert an. Der historische Roman behandelt nach seiner Definition

geschichtliche Ereignisse und Personen, in einer Sonderform kulturgeschichtliche Hintergründe einer erfundenen Handlung, in freikünstlerischer Prosagestaltung und geben je nach Art des gewählten Stoffs und der Darstellungsweise einen individuellen Lebenslauf oder ein allgemeines Geschichtsbild, das jedoch wegen dichterischer Freiheiten nicht immer das wissenschaftlich anerkannte, sondern auch ein intuitiv erfühltes, doch glaubwürdiges oder nach ästhetischen Gesichtspunkten umgestaltetes sein kann. ${ }^{397}$

Eine andere Definition unterstreicht ebenfalls das Auftreten von historischen Ereignissen und Gestalten als ein charakteristisches Merkmal des historischen Romans. „Historischer Roman gründet Fabel auf historische Persönlichkeiten oder Geschehnisse beziehungs-

${ }^{394}$ Literaturwissenschaftliches Lexikon, S. 125.

${ }^{395}$ Reallexikon der deutschen Literaturgeschichte. Begr. v. Paul Merker u. Wolfgang Stammler, hrsg. v. Werner Kohlschmidt und Wolfgang Mohr. Berlin, New York: de Gruyter 2001 (2. Aufl.), Bd. 1, S. 658.

${ }^{396}$ Vogel, Alois: Antworten auf die Fragen zum Referat im Dissertantenkolloquium von Professor Wendelin Schmidt-Dengler am 9.6.1998, s. Anhang.

${ }^{397}$ Sachwörterbuch der Literatur, S. 378. 
weise benutzt historische Überlieferung als Hintergrund für fiktive Handlung." ${ }^{\text {“398 }}$

Die erste Kategorie wäre also das Hineinversetzen der Handlung in eine Zeit, in der geschichtliche Ereignisse, begleitet von geschichtlichen Gestalten, vorkommen. Diese Kategorie scheint in den behandelten Vogelschen Romanen im Großen und Ganzen erfüllt. Anmerken muss man jedoch, dass es hier zwar einen historischen Hintergrund gibt, die bekannten historischen Persönlichkeiten sind jedoch nicht die Hauptakteure, sondern befinden sich am Rande der eigentlichen Handlung, die von fiktiven Gestalten getragen wird. ${ }^{399}$ Nach der Unterteilung der historischen Dichtung von Victor Klemperer sei das nicht die eigentliche und erfüllte historische Dichtung, denn eine solche hat im Zentrum bekannte historische Persönlichkeiten, alles andere sei kulturhistorisches Schildern. ${ }^{400}$

Als weitere Kategorie soll die temporale Distanz zwischen Romanpublikation und dargestellter Zeit genannt werden. Diese resultiert aus der Überlegung, wie weit ein epischer Stoff von der Gegenwart des Schreibenden entfernt sein muss, um als historisch gelten zu können. Dazu gibt es auch unterschiedliche Ansichten.

Es wird angenommen, dass der Zeitabstand zumindest sechzig Jahre, das heißt also zwei Generationen beträgt. Inzwischen wurde diese Zeitspanne auf dreißig Jahre beschränkt. ${ }^{401}$ Vogels Romane würden nur die zweite Bedingung erfüllen, denn bei Schlagschatten beträgt diese zeitliche Distanz circa 43, bei Totale Verdunkelung circa 35 Jahre. Die Tatsache, dass besonders im Falle des ersten Romans elf Jahre vergingen, bis er erschien, bleibt dabei unberücksichtigt. Die These vom dreißig- beziehungsweise sechzigjährigen Abstand wird

${ }^{398}$ Handbuch literarischer Fachbegriffe. Definitionen und Beispiele, hrsg. v. Otto F. Best. Frankfurt a. M.: Fischer 1994, S. 231.

${ }^{399}$ s. Historische Persönlichkeiten (5.2.3 Unterkapitel dieser Arbeit).

${ }^{400}$ Die hauptsächliche Schwierigkeit, die historische Dichtung zu überwinden hat, sei - nach Klemperer - die Bestimmtheit des Stoffes. Der Dichter kann das auf dreifache Weise tun. Er kann sich auf die Bestimmtheit des Vorfalls beschränken, seine Geschichte etwa in die Zeit des dreißigjährigen Krieges verlegen, ihr aber private, nur durch jene Zeitereignisse mitbestimmte Helden geben. Zweitens kann er den privaten Helden im Mittelpunkt des Erzählten beibehalten, peripher aber die großen Gestalten der Zeit auftauchen lassen. Die dritte Möglichkeit ist die oben beschriebene. Alois Vogels historische Romane würde ich der zweiten Gruppe zuschreiben. Vgl. Klemperer: Die Arten der historischen Dichtung, S. $377 f$.

${ }^{401}$ Kohpeiß: Der historische Roman der Gegenwart, S. 31. 
von Lion Feuchtwanger umgestoßen, der zeigt, dass auch Romane, die nicht in Epochen vor der Lebenszeit des Verfassers spielen, als historische Romane angesehen werden können, vorausgesetzt, dass „die Zeit ihrer Handlung durch ein entscheidendes Ereignis getrennt ist von der Zeit der Entstehung. "402 Diese Ansicht könnte in Bezug auf die Romane Alois Vogels zutreffen, denn der Zweite Weltkrieg bildet in beiden Fällen eine ausreichende Zäsur zwischen der Zeit der Handlung und der Zeit der Entstehung dieser Werke. Im ersten Roman ist dieser zeitliche Abstand sogar noch größer (über vierzig Jahre). Eine ähnliche Ansicht vertritt Hermann Sottong. Er stellt fest, dass eine der drei Voraussetzungen, die erfüllt werden müssen, um einen Roman als historisch qualifizieren zu können, eine Aufnahme durch die zeitgenössische Leserschaft sei, die den dargestellten Zeitraum als historischen, als von seiner eigenen unterschiedenen Phase oder Epoche empfinde. Er weist darauf hin, dass es recht unterschiedlich interpretiert werden könne, wie groß dieser Abstand sein solle und dass er vom Denksystem der Kultur abhängig sei. So sei zum Beispiel bereits in den fünfziger Jahren des zwanzigsten Jahrhunderts die Zeit des Krieges und des Nationalsozialismus für die Mehrheit der Bevölkerung zur Vergangenheit geworden. ${ }^{403}$

$\mathrm{Da}$ die beiden behandelten Romane Alois Vogels im Allgemeinen die oben genannten Kategorien erfüllen, könnte man sie als historische Romane bezeichnen. Ausschlaggebend ist auch die Intention und die tiefe Überzeugung des Autors, einen historischen Roman zu schreiben. Die beste Lösung für dieses Problem scheint zu sein, diese Romane als Zeitgeschichtsromane zu bezeichnen, wobei Zeitgeschichte hier als "Epoche der Mitlebenden" verstanden wird, das heißt die Zeit, auf die Autor und Leser selbst zurückgreifen können. Ralph Kohpeiß weist darauf hin, dass der Begriff ,Zeitgeschichtsroman" als Hilfskategorie und als Instrument zur Strukturierung der Werkmassen im Grenzbereich zwischen Zeitroman und historischem Roman gilt. ${ }^{404}$

${ }^{402}$ Feuchtwanger: Das Haus der Desdemona, S $117 \mathrm{f}$.

${ }^{403}$ Sottong, Hermann, J.: Transformation und Reaktion. Historisches Erzählen vor der Goethezeit zum Realismus. Fink 1992 (=Münchner Germanistische Beiträge, Bd. 39), S. 15.

${ }^{404}$ Kohpeiß: Der historische Roman der Gegenwart, S. 32. 
5.12. Charakteristika der Romane Schlagschatten und Totale Verdunkelung von Alois Vogel - Zusammenfassung

- Begrenzte Zahl der Protagonisten, die fiktive Gestalten sind und an die „mittleren Helden“, wie sie bei Scott zu finden sind, erinnern. Sie sind Träger der Handlung, die nicht auf einfacher Abfolge von Ereignissen beruht, sondern durchtrennt ist von unzähligen Rückblenden, die eine zeitlich retardierende Funktion erfüllen und gleichzeitig zur Charakterisierung der Personen entschieden beitragen. Die Protagonisten erleben geschichtliche Ereignisse als Beobachter, die Romane sind daher auch Geschichten ihrer Entwicklung, wobei in Schlagschatten die menschliche Entwicklung Richard Wohllebens und in Totale Verdunkelung die Franz Prannowitz' im Zentrum steht. Sie werden von der Geschichte, die sie erleben, nicht völlig determiniert, ihre Erlebnisse tragen jedoch dazu bei, dass in den Protagonisten bestimmte Entscheidungen schneller reifen. Sie werden dadurch nicht vollkommen neue Menschen, die Begegnung mit der Geschichte stellt aber den Höhepunkt ihrer menschlichen Entwicklung dar. Die Darstellungsweise der Geschichte könnte man als „Geschichte aus der Sicht eines einfachen Menschen" bezeichnen, was die Absicht des Autors gewesen ist. Die Erzähltechnik sowie das Inhaltliche bestätigen diese Intention. So steht zum Beispiel der individuelle und nicht der organisierte Widerstand im Mittelpunkt.

- Das möglichst seltene Auftreten von bekannten historischen Persönlichkeiten, die völlig am Rande stehen. Situationen, in denen ein Protagonist mit einer bekannten historischen Persönlichkeit in Berührung kommt, sind Ausnahmefälle. Es kommen aber viele Gestalten vor, die zwar keine bekannten historischen Persönlichkeiten sind, in der damaligen Zeit jedoch eine wesentliche Rolle gespielt haben. Solche Personen treten in den Romanen unter einem anderen Namen auf, exemplifizieren aber wirklich existierende Personen, die den Romangestalten Vorbild standen, so zum Beispiel Oberstleutnant Perkal, der als Vertreter der Widerstandsbewegung in Totale Verdunkelung fungiert. Andererseits stellt der Autor fest, dass persönliche Schicksale frei erfunden sind und es Zufall ist, wenn sie sich mit vielen Persön- 
lichkeiten decken oder zum Teil decken. ${ }^{405}$ Historische Persönlichkeiten erscheinen - mit einer Ausnahme - eigentlich nur in der Reflexion der Romanfiguren, in ihren Erinnerungen, Gedanken oder Gesprächen. Oft wird die „Zeitungskonvention“ verwendet, das heißt eine Romangestalt liest einen Zeitungsartikel oder findet zufällig an ganz überraschenden Stellen, wie zum Beispiel in einer Toilette oder einem Geräteschuppen, Zeitungsfetzen, die dort praktischen Zwecken dienen und auf diese Weise die auf den Bildern dargestellten „historischen Größen“ schmälern. Es gibt keine Mächtigen, die vom Spott des Autors verschont blieben, eine Ausnahme bilden lediglich die Regierungen der Ersten Republik.

- Historische Ereignisse als solche werden nicht in ihrer Breite dargestellt, die Handlung der Romane spielt entweder zwischen wichtigen Ereignissen (wie in Schlagschatten, wo nur einer der Protagonisten, Richard Wohlleben, während des Juliputsches 1934 direkt damit in Berührung kommt) oder gegen Ende solcher Ereignisse (wie in Totale Verdunkelung am Ende des Zweiten Weltkrieges). Historische Ereignisse bilden den Hintergrund für die Taten und Entscheidungen der Protagonisten, diese Entscheidungen treffen sie aber unabhängig von der Zeit, in der sie leben. Die sich im Hintergrund abspielende Geschichte bewirkt, dass die Taten und Entscheidungen der Romangestalten dramatischer wirken, sie dient dem Kontrast zwischen der düsteren Wirklichkeit und den Handlungen der Protagonisten und damit einer positiven Einschätzung der Menschen.

- Genaue Fixierung des Handlungsortes, der eine genaue Bestimmung der gesellschaftlichen Zugehörigkeit von Protagonisten und dadurch ihre bessere Charakterisierung ermöglicht. Man kann die Handlungsorte mit großer Genauigkeit auf der Karte nachskizzieren. Der Hauptteil der Handlung der beiden Romane spielt - wie mit Ausnahme des ersten, alle Romane Alois Vogels - in einigen Wiener Bezirken.

${ }^{405}$ Brief Alois Vogels v. 3.7.2000. 
- Durch viele Geschichtssignale entschlüsselbare Handlungszeit und verschiedene Zeitebenen, die die nötige Zeitdistanz und damit erst den Eindruck des Vergangenen erzeugen. Die Zeitgeriiste beider Romane weisen bestimmte Parallelen auf: die Schilderung des ersten Tages, die von Erinnerungen, Gesprächen und Gedanken der auftretenden Personen unterbrochen wird, dann in eine nicht näher bestimmbare Zeitspanne übergeht, die einige Monate oder Wochen zusammenfasst um dann an einem genau fixierten Tag den Höhepunkt zu erreichen und einige Zeit danach auszuklingen.

- In beiden Romanen hat man mit unterschiedlichen Methoden der Zeitbestimmung zu tun. Die Zeit wird vor allem bestimmt durch Wetter und Natur oder durch sich gerade abspielende Geschehnisse oder historische Ereignisse, die in den Gesprächen oder in der Zeitungslektüre der Protagonisten Niederschlag finden. Am Anfang des zweiten Romans dominiert die zeitliche Bestimmung durch Naturerscheinungen, je mehr sich jedoch das Kriegsende nähert, desto nachhaltiger wird die Zeit durch die sich gerade abspielenden Ereignisse bestimmt. Ein exaktes Datum kommt äußerst selten vor.

- In beiden Texten gibt es kaum Erkennungszeichen eines historischen Romans im Sinne Hugo Austs ${ }^{406}$ wie amtliche Dokumente, Fußnoten, Anmerkungen, Landkarten, Zeittafeln oder Bibliographie. Zeitwert besitzen, nach Aust, auch Namen, Begriffe und andere kulturhistorische Details, die in den behandelten Romanen, vor allem in Schlagschatten, eher vereinzelt auftreten. Totale Verdunkelung ist viel stärker zeitgeschichtlich verankert.

- Anschein der Objektivität durch dreifache, unterschiedlich ausführliche Perspektive in Schlagschatten ${ }^{407}$ und Doppelperspektive in Totale Verdunkelung (einige Szenen).

${ }^{406}$ Aust: Der historische Roman, S. 22-32.

${ }^{407}$ s. die Seitenlänge der Darstellung derselben Situation aus drei Perspektiven ist in den Kapiteln Richard, Leni und Hans nicht gleich und umfasst jeweils ca. 6, 2 und eine halbe Seite. Das ist übrigens eine einzige Szene, die aus drei Perspektiven geschildert wird. Sonst gibt es parallele Schilde- 
- Reichtum an Symbolik, die tief in der Natur verwurzelt ist; die Romantitel fungieren als Symbole. Dabei soll angemerkt werden, dass Schlagschatten reicher an symbolhaften Handlungen ist, während Totale Verdunkelung in viel direkterer Weise auf die Zeitgeschichte Bezug nimmt.

- Eines der wichtigsten Probleme jedes historischen Romans und als solche werden die Romane von Alois Vogel behandelt ist das komplexe Verhältnis zwischen der Verarbeitung der Opposition von Fiktion und Historie. Bei Vogel überwiegt die Stimmigkeit mit den historischen Tatsachen, was den gründlichen Studien der Zeitungen der Zeit und anderer Quellen sowie den Gesprächen, die der Autor mit Zeitzeugen durchgeführt hat, zu verdanken ist. Diese Tatsache führt zur Annahme, dass die Romane von Alois Vogel nach der Theorie von Hans Vilmar Geppert den Hiatus zwischen Fiktion und Geschichte nicht akzentuieren. Daher wären sie - im Verständnis von Geppert - „typische“ historische Romane im Gegensatz zu ,anderen“ historischen Romanen, in denen versucht wird, den Hiatus schöpferisch zu gestalten. Die Aussage des Autors scheint diese These zu unterstützen. ${ }^{408} \mathrm{Da}$ aber die Fakten äußerst selten direkt beim Namen genannt und wirklich existierende Gestalten hinter fiktiven verdeckt werden, (s. Oberstleutnant Perkal oder den Bruder Richard Wohllebens, Erich) könnte dies auch bedeuten, dass hier der Hiatus akzentuiert oder zumindest nicht verdeckt wird. Damit sind bestimmte Erwartungen an den Leser verbunden, konkretes Wissen wird gefordert, um diese Zusammenhänge entdecken zu können.

- Kompositorisch gesehen sind diese Romane aber keine traditionellen historischen Romane im Sinne Gepperts. Die Verschachtelungen der Handlung und der Orte, die große Anzahl an Rückblenden, Technik des Stream of consciousness in Verbindung mit der Aufhebung des zeitlichen Nacheinanders, Durchdringung mit Symbolen und Symbolketten macht die „Technik

rungen jeweils in den Kapiteln Richard - Leni und Leni-Hans, was das Schwanken dieser Frau zwischen den beiden Männern veranschaulicht. ${ }^{408}$ Antworten Alois Vogels auf Fragen zum Dissertantenkolloquium am 9.6.1998. 
der assoziativen Retrospektive ${ }^{409}$ aus - ein Begriff, der von August Obermayer in Bezug auf die Romane Alois Vogels eingeführt wurde.

${ }^{409}$ Obermayer: Nachwort zum 4. Band der 5-bändigen Werkausgabe, S. 487. 